\title{
Article \\ A Novel Adaptive Sparrow Search Algorithm Based on Chaotic Mapping and T-Distribution Mutation
}

\author{
Xiaoxu Yang ${ }^{1}$, Jie Liu ${ }^{2}$, Yi Liu ${ }^{3}$, Peng Xu ${ }^{4}$, Ling Yu ${ }^{5}$, Lei Zhu ${ }^{5}$, Huayue Chen ${ }^{6, *}$ and Wu Deng ${ }^{1, *}$ \\ 1 College of Electronic Information and Automation, Civil Aviation University of China, Tianjin 300300, China; \\ 2019021059@cauc.edu.cn \\ 2 Anhui CQC-CHEARI Technology Co., Ltd., Chuzhou 239000, China; liujie@cheari.com \\ 3 Research Center of Big Data and Information Management, Civil Aviation Management Institute of China, \\ Beijing 100102, China; liuyi@camic.cn \\ 4 Chuzhou Technical Supervision and Testing Center, Chuzhou 239000, China; X743045850@163.com \\ 5 China Household Electric Appliance Research Institute, Beijing 100176, China; yul@cheari.com (L.Y.); \\ zhul@cheari.com (L.Z.) \\ 6 School of Computer Science, China West Normal University, Nanchong 637002, China \\ * Correspondence: sunnyxiaoyue20@cwnu.edu.cn (H.C.); wdeng@cauc.edu.cn (W.D.)
}

Citation: Yang, X.; Liu, J.; Liu, Y.; Xu, P.; Yu, L.; Zhu, L.; Chen, H.; Deng, W. A Novel Adaptive Sparrow Search Algorithm Based on Chaotic Mapping and T-Distribution Mutation. Appl. Sci. 2021, 11, 11192. https://doi.org/10.3390/app112311192

Academic Editors: Giancarlo Mauri and Eui-Nam Huh

Received: 27 September 2021

Accepted: 23 November 2021

Published: 25 November 2021

Publisher's Note: MDPI stays neutral with regard to jurisdictional claims in published maps and institutional affiliations.

Copyright: () 2021 by the authors. Licensee MDPI, Basel, Switzerland. This article is an open access article distributed under the terms and conditions of the Creative Commons Attribution (CC BY) license (https:// creativecommons.org/licenses/by/ $4.0 /)$.

\begin{abstract}
Aiming at the problems of the basic sparrow search algorithm (SSA) in terms of slow convergence speed and the ease of falling into the local optimum, the chaotic mapping strategy, adaptive weighting strategy and $\mathrm{t}$-distribution mutation strategy are introduced to develop a novel adaptive sparrow search algorithm, namely the CWTSSA in this paper. In the proposed CWTSSA, the chaotic mapping strategy is employed to initialize the population in order to enhance the population diversity. The adaptive weighting strategy is applied to balance the capabilities of local mining and global exploration, and improve the convergence speed. An adaptive t-distribution mutation operator is designed, which uses the iteration number $t$ as the degree of freedom parameter of the $t$ distribution to improve the characteristic of global exploration and local exploration abilities, so as to avoid falling into the local optimum. In order to prove the effectiveness of the CWTSSA, 15 standard test functions and other improved SSAs, differential evolution (DE), particle swarm optimization (PSO), gray wolf optimization (GWO) are selected here. The compared experiment results indicate that the proposed CWTSSA can obtain higher convergence accuracy, faster convergence speed, better diversity and exploration abilities. It provides a new optimization algorithm for solving complex optimization problems.
\end{abstract}

Keywords: sparrow search algorithm; chaotic mapping; adaptive weight; t-distribution mutations; multi-strategy; global optimization

\section{Introduction}

In recent decades, in order to solve some complex optimization problems, many bionic swarm intelligence optimization algorithms have emerged, such as the ant colony algorithm (ACO), particle swarm optimization (PSO), artificial bee colony algorithm (ABC), genetic algorithm (GA), sparrow search algorithm (SSA), grey wolf optimization (GWO), differential evolution (DE), and so on [1-5]. The principle of these algorithms is simple and easy to implement, so they have attracted more and more attention [6-9]. Ma et al. [10] proposed an adaptive ant colony optimization algorithm based on an optimized guidance search mechanism to effectively solve the dynamic traveling salesman problem. Ang et al. [11] proposed a speed-free multi-swarm particle swarm optimization, which overcomes the premature convergence caused by the limited search operator and the direction information used to guide the search process, and improved the stability. Li et al. [12] proposed an improved artificial bee colony algorithm (IABC). The proposed IABC uses a two-level encoding and machine-selected decoding method combined with a hybrid 
search strategy of simulated annealing to maintain the diversity of the solution space and improve computational efficiency. Gao et al. [13] proposed a multi-independent population genetic algorithm (MGA) combined with a subdomain model to improve the magnetic field distribution, cost, and efficiency of SPMSM, which proves the advantages of the MGA optimization method. In addition, some new algorithms also have been proposed in recent years [14-23]. As a new algorithm of bionic swarm intelligence, the sparrow search algorithm was proposed by Xue and Shen [24] in 2020. It was inspired by sparrow foraging behavior, anti-predation behavior, and swarm intelligence. Compared with some other swarm intelligence algorithms, the SSA has stronger optimization capabilities and faster search efficiency, good stability, and strong robustness. It has been used in UAV trajectory planning [25] and image segmentation [26]. When the algorithm search is close to the global optimum, there will be problems, such as reduced population diversity and ease of falling into local optimum. In order to overcome these shortcomings, many scholars have carried out extensive research work to improve the optimization performance of the SSA. Their work mainly includes population initialization, designing mutation strategies, and combining other optimization algorithms.

A single algorithm cannot solve all types of problems. A hybrid mechanism can be used to integrate the advantages of other algorithms and introduce them into the sparrow search algorithm, making full use of their respective advantages to search collaboratively to enhance the overall optimization capability of the SSA. Du et al. [27] introduced a good point set theory in number theory to improve the SSA algorithm, so that the initial population is uniformly and evenly distributed in the solution space and the convergence speed is improved. Zhang et al. [28] designed a chaotic sparrow search algorithm to enhance the global optimization capability for stochastic configuration networks. Liu et al. [29] proposed a new balanced sparrow search algorithm to improve the efficiency of the CNN concerning consistency and accuracy. Liu et al. [30] proposed a modified sparrow search algorithm to deal with the unmanned aerial vehicle route planning problem. Zhang et al. [31] proposed an improved sparrow search algorithm with three new strategies for a bioinspired path planning approach for mobile robots. Wang et al. [32] proposed an improved sparrow search algorithm for a hydrological neural network hybrid model. Liang et al. [33] proposed a new intelligent optimization algorithm called the sparrow search algorithm (SSA) and its modification for the electromagnetics and antenna community. Zhu and Yousefi [34] proposed a new adaptive sparrow search algorithm for optimal model parameter identification of proton exchange membrane fuel cell stacks. Yuan et al. [35] proposed an improved sparrow search algorithm for distributed maximum power point tracking. Ouyang et al. [36] proposed an adaptive spiral flying sparrow search algorithm, which reduces the probability of getting stuck into local optimum and has stronger optimization ability than other algorithms. Yang et al. [37] combined the PSO algorithm with SSA algorithm to speed up the convergence speed before the SSA individual update. Liu et al. [38] proposed an enhanced SSA algorithm based on reverse learning and work function mechanism to improve the search conditions. Xing et al. [39] used the SSA algorithm to perform multi-component fault diagnosis on wheelset bearings. Wang et al. [40] proposed a dynamic adaptive SSA algorithm based on Bernoulli chaotic mapping, the SSA algorithm of weighting, Cauchy mutation and reverse learning to improve the efficiency of microgrid clusters.

Compared with other algorithms, the SSA has higher stability and better convergence accuracy. It can escape falling into the local optimum to a certain extent. However, due to the fast convergence rate, there is still a probability that no feasible solution can be obtained. In order to solve these existing problems, a novel adaptive SSA algorithm based on the chaotic mapping strategy, adaptive weighting strategy and t-distribution mutation strategy is proposed in this paper. The sine chaotic mapping strategy is employed to initialize the population in order to reduce the impact of population randomness, and then the adaptive weighting strategy is used to better perform the global search. The $t$-distribution mutation strategy is used to update the position of the individual sparrow in order to find 
a more reliable and feasible solution and improve the optimization performance of the SSA algorithm.

The innovations and main contributions of this paper are described as follows.

- A novel CWTSSA based on the strategies of chaotic mapping, adaptive weighting and $\mathrm{t}$-distribution mutation is developed to effectively solve the complex optimization problem.

- The sine chaotic mapping strategy is used to initialize the population in order to enhance the diversity of the population.

- The adaptive weighting strategy is applied to balance the capabilities of local mining and global exploration, and improve the convergence speed.

- The adaptive $t$-distribution mutation operator is designed to improve the characteristic of global exploration and local exploration abilities, so as to avoid falling into the local optimum.

- Comprehensive experiments are designed and executed to comprehensively prove the effectiveness of the CWTSSA by 15 standard test functions.

\section{Basic SSA}

The SSA algorithm is a new swarm intelligence optimization algorithm, which is inspired by foraging behavior of sparrows, anti-predation behavior and swarm intelligence. The foraging process of sparrows can be visually abstracted as a discoverer-joiner model. The discoverer is responsible for looking for food for the population and providing foraging areas and directions for the entire sparrow population, while joiners obtain food by taking advantage of discovers. In order to obtain food, sparrows can usually forage for food using two behavioral strategies: discoverer and joiner. Individuals will monitor the behavior of other individuals in the population, and attackers will compete with high-intake companions for food resources to increase their predation rate. In addition, when the sparrow population is aware of danger, it will assume anti-predator behavior.

The matrix representation of the sparrow set is described as follows.

$$
\begin{gathered}
X=\left[x_{1}, x_{2} \ldots x_{N}\right]^{T} \\
x_{i}=\left[x_{i, 1}, x_{i, 2}, \ldots, x_{i, d}\right]
\end{gathered}
$$

where, $X$ represents the size of the sparrow population, and $d$ represents the dimension of the variable.

The fitness matrix of the sparrow is expressed as follows.

$$
\begin{aligned}
f\left(x_{i}\right) & =\left[f\left(x_{i, 1}\right), f\left(x_{i, 2}\right), \ldots, f\left(x_{i, d}\right)\right] \\
F_{x} & =\left[f\left(x_{1}\right), f\left(x_{2}\right) \ldots f\left(x_{N}\right)\right]^{T}
\end{aligned}
$$

where, $N$ represents the size of the sparrow population, $f\left(x_{i}\right)$ represents the fitness value of each individual, and $F_{x}$ represents matrix of individual fitness values.

The sparrow with the best fitness value is given priority to get food, and points out the direction to the food for other individuals as the discoverer. The location of the discoverer is updated as follows.

$$
X_{i, j}^{t+1}= \begin{cases}X_{i, j}^{t} \cdot \exp \left(\frac{-i}{\alpha \cdot i t e r_{\max }}\right), & \text { if } R_{2}<S T \\ X_{i, j}^{t}+Q \cdot L, & \text { if } R_{2} \geq S T\end{cases}
$$

where, $t$ represents the current number of iterations, $j=(1,2, \ldots, d)$, and $X_{i, j}^{t+1}$ represents the position of the $i$-th sparrow in the $j$-th position. iter $_{\text {max }}$ represents the maximum number of iterations. $\alpha \in(0,1), \alpha$ is a random number in the range. $R_{2}$ and $S T$ represent the pre-warning and safety values, respectively. $Q$ is a random number between 0 and 1 . $L$ is a $1 \times \mathrm{d}$ matrix of all elements with the value of 1 . When $R_{2}<S T$, it means safety, and 
the discoverer conducts an extensive search mode. When $R_{2} \geq S T$, it means that some sparrows have detected natural enemies and need the entire population to go to other safe areas as soon as possible.

The location of the joiner is updated as follows.

$$
X_{i, j}^{t+1}=\left\{\begin{array}{lc}
Q \cdot \exp \left(\frac{X_{\text {worst }}^{t}-X_{i, j}^{t}}{t^{2}}\right) & i>\frac{N}{2} \\
X_{p}^{t+1}+\left|X_{i, j}^{t}-X_{p}^{t+1}\right| \cdot A^{+} \cdot L & \text { other }
\end{array}\right.
$$

where, $X_{P}$ represents the optimal position of the discoverer. $X_{\text {worst }}^{t}$ denotes the global worst location. A is a matrix of $1 \times d$, in which each element is randomly assigned 1 or -1 . When $i>N / 2$, it suggests that the $i$-th joiner with the worse fitness value is most likely to be starving. The energy value is lower, and they need to go to other areas to find food to supplement their energy.

Detection and early warning sparrows are aware of danger, and generally account for $10 \sim 20 \%$ of the total number of sparrows. Location updates are described as follows.

$$
X_{i, j}^{t+1}=\left\{\begin{array}{cl}
X_{b e s t}^{t}+\beta \cdot\left|X_{i, j}^{t}-X_{b e s t}^{t}\right| & \text { if } f_{i}>f_{g} \\
X_{i, j}^{t}+K \cdot\left(\frac{\left|X_{i, j}^{t}-X_{w o r s t}^{t}\right|}{\left(f_{i}-f_{w}\right)+\varepsilon}\right) & \text { if } f_{i}=f_{g}
\end{array}\right.
$$

where, $X_{\text {best }}^{t}$ is current global optimal position. $\beta$ is a normal distribution of random numbers with a mean value of 0 and a variance of 1 , which is regarded as the step size control parameter. $K \in[-1,1]$ is a random number. Here, $f_{i}$ represents the fitness value of the current individual. $f_{i}$ and $f_{w}$ are the current global best value and worst fitness value, respectively. $\varepsilon$ is the smallest arbitrary number, which is used to avoid zeros in the denominator. $K$ represents the direction in which the sparrow is moving.

\section{A Novel Adaptive Sparrow Search Algorithm}

The mutation strategy in SSA directly affects the exploration ability, convergence accuracy and speed. Therefore, strategy selection is very important for the performance of the SSA algorithm. Compared with other bionic algorithms, the SSA has better optimization performance in solving complex optimization problems, but it has the shortcomings of reduced population diversity and insufficient convergence accuracy. In order to overcome these shortcomings, the chaotic mapping strategy, adaptive weighting strategy and $\mathrm{t}$ distribution mutation strategy are introduced in order to develop a novel adaptive sparrow search algorithm based on a multi-strategy fusion mechanism (CWTSSA) in this paper. In the proposed CWTSSA, the chaotic mapping strategy is employed to initialize the population in order to enhance the population diversity. The adaptive weighting strategy is applied to balance the capabilities of local mining and global exploration and improve the convergence speed. The adaptive $t$-distribution mutation operator is designed to improve the characteristic of global exploration and local exploration abilities, so as to avoid falling into the local optimum.

\subsection{Sine Chaotic Mapping Strategy for Initialization Population}

The SSA algorithm uses a random initialization method to determine the initial position of the sparrow. Although the randomness of the initial position is guaranteed, the optimal value of the initial position of some individuals is too far from the optimal value, which reduces the convergence speed and solution accuracy. However, the pseudo random number generator (PRNG) has good statistical and random characteristics, which are regarded as ideal information sources. Adaptive chaotic mapping is a good candidate for pseudo-random number generation with high randomness and easy implementation. Some pseudo-random number algorithms for chaotic systems have been proposed in recent years [41]. Therefore, the sine chaotic map is employed to initialize the population of the 
SSA algorithm, and the advantages of the randomness and initial sensitivity of the chaotic sequence are used to effectively make up for the shortcomings of the random initialization method. The expression of the sine chaotic map is described as follows.

$$
x_{n+1}=\frac{a}{4} \sin \left(\pi x_{n}\right) \quad a \in(0,4]
$$

where, $a$ represents the control parameter, and $x_{n}$ represents the value of the mapping function. Sine mapping is a unimodal mapping with a value range of $[-1,1]$.

\subsection{Dynamic Adaptive Weighting Strategy}

In the early stage of the SSA, the discoverer approaches the global optimal solution, which makes the search range too small and the search space insufficient, increasing the ease of the algorithm falling into the local optimum and resulting in insufficient search accuracy. In this paper, the global optimal solution of the previous generation in the update of the discoverer's position is introduced, so that the position of the discoverer is not only affected by the position of the previous generation, but also by the global optimal solution of the previous generation, which can effectively prevent the algorithm from falling into the local optimal solution. In addition, in order to perform a better local search, with the help of the idea of inertial weight, the dynamic weight factor is introduced to better perform the global search. It has a larger value at the beginning of the iteration, and it is the adaptively reduced at the later stage of the iteration. Simultaneously, it can also increase the speed of convergence.

The calculation expression of the weight coefficient and the improved updating location method of the discoverer are described as follows.

$$
\begin{gathered}
\omega=\frac{e^{2\left(1-t / \text { iter }_{\max }\right)}-e^{-2\left(1-t / \text { iter }_{\max }\right)}}{e^{2\left(1-t / \text { iter }_{\max }\right)}+e^{2\left(1-\text { titer }_{\max }\right)}} \\
X_{i, j}^{t+1}= \begin{cases}X_{i, j}^{t}+\omega\left(f_{i, g}^{t}-X_{i, j}^{t}\right) \cdot \text { rand } & R_{2}<S T \\
X_{i, j}^{t}+Q & R_{2} \geq S T\end{cases}
\end{gathered}
$$

\subsection{T-Distribution Mutation Strategy}

In probability theory and statistics, t-distribution is also called student distribution. It is used to estimate the mean of a normally distributed population with unknown variance based on a small sample. The shape of the $t$-distribution curve is related to the degree of freedom n. Compared with the standard normal distribution, if the degree of freedom is smaller, the curve is flatter. If the middle of the curve is lower, the tails on both sides of the curve are higher. If the degree of freedom $\mathrm{n}$ is greater, the $\mathrm{t}$-distribution is closer to the normal distribution. The Cauchy distribution and Gaussian distribution are two special case distributions at the boundary of the t-distribution, and the three function distributions are shown in Figure 1.

It can be seen from Figure 1 that the shape of the two ends of the t-distribution is long and flat, and the process of approaching 0 is relatively gentle. The speed is slower than the Cauchy and Gaussian distributions, and the peak is similar to the Cauchy and Gaussian. The distribution is smaller than those, such that the t-distribution variation is stronger than the Cauchy variation and Gaussian variation in perturbation ability. Therefore, the $\mathrm{t}$-distribution mutation is introduced into the target position update formula, and the disturbance ability of the $\mathrm{t}$-distribution mutation is exerted to improve the global optimization performance. The adaptive t-distribution mutation strategy is used to update the sparrow position, which is described as follows.

$$
x_{i}^{t}=x_{i}+x_{i} \cdot t(\text { iter })
$$


where, $x_{i}^{t}$ represents the individual position of the sparrow after mutation, $x_{i}$ is the position of the sparrow individual, and $t($ iter $)$ denotes the t-distribution with the number of iterations, which is regarded as the parameter degree of freedom. On the basis of this definition, the $\mathrm{t}$-distribution random interference term is added to make full use of the information interference of the current population, and the number of iterations $t$ is used as the degree of freedom parameter. At the beginning of the algorithm, the value of the number of iterations is small, the t-distribution mutation is similar to that of Cauchy distribution mutation, and the algorithm has good global exploration ability. In the later period of the algorithm, the t-distribution mutation is similar to the Gaussian distribution mutation, and the algorithm has good local development capabilities. In the middle of the algorithm, the $\mathrm{t}$-distribution mutation is between Cauchy mutation and Gaussian mutation. The mutation operator of the t-distribution combines the advantages of the Gaussian operator and the Cauchy operator, and the global exploration and local exploration of the algorithm are improved at the same time.

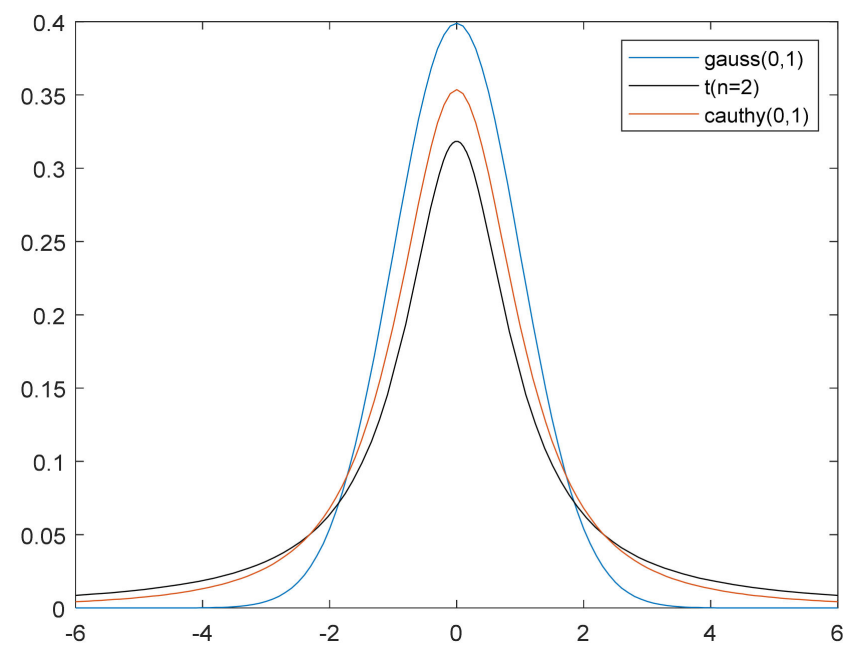

Figure 1. Probability density curves of Cauchy, Gaussian and t-distribution.

\subsection{The Model of the CWTSSA}

A novel adaptive sparrow search algorithm based on chaotic mapping and t-distribution mutation, namely the CWTSSA, is proposed. Its features enable the CWTSSA to avoid falling into the local optimum, and also improve the convergence speed and accuracy. The flow of the CWTSSA is shown in Figure 2.

The specific steps of the CWTSSA are described in detail as follows.

Step 1. Initialize parameters of the CWTSSA, including population size, maximum number of iterations, proportion of discoverers, proportion of scouts, and the sparrow population using sine mapping.

Step 2. Calculate the fitness value of each sparrow to find the current optimal fitness value and the worst fitness value, and their corresponding positions.

Step 3. From the sparrows with better fitness values, some sparrows are selected as discoverers, and the position is updated according to the weight update strategy.

Step 4 . The remaining sparrows are used as joiners, and their positions are updated.

Step 5. Randomly select some sparrows as guards and update their positions.

Step 6. If rand $<$, adaptive $t$-distribution mutation is performed according to formula (11), the current optimal value is disturbed, and a new solution is generated.

Step 7. Calculate fitness value and update position.

Step 8. Determine whether the conditions are met, and output the results if they are met. Otherwise repeat the Step 2 until the end condition is met. 


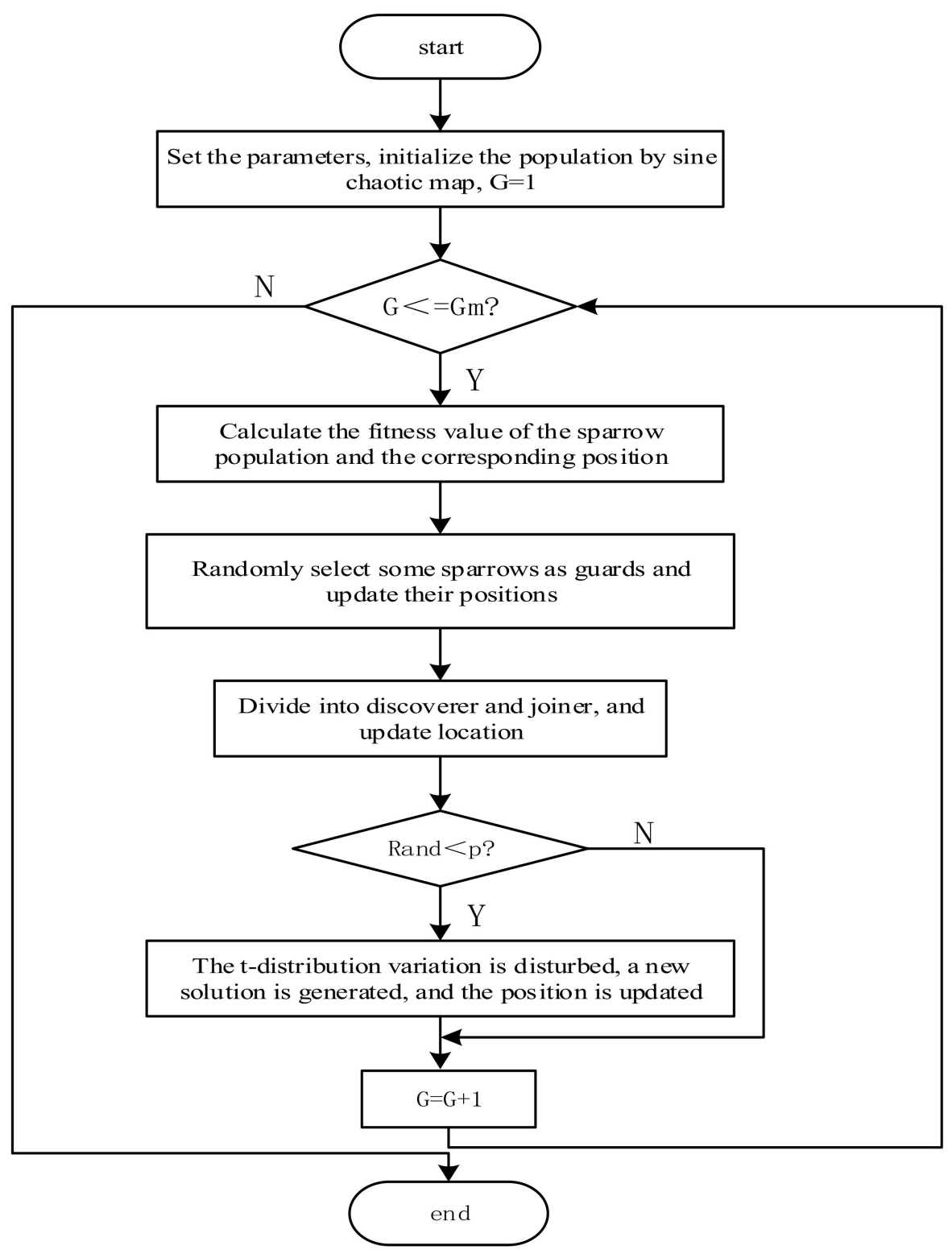

Figure 2. The flow of the CWTSSA.

\section{Numerical Experiments and Analysis}

\subsection{Test Functions}

In order to test and prove the optimization performance of the CWTSSA, 15 standard test functions from CEC2008, CEC2017 and CEC2020 are selected here. The function types include unimodal functions, multimodal functions and compound functions. The detailed representation of the test function is shown in Table 1. Usually, it is difficult to have an accurate evaluation with a small number of experiments. Therefore, each function was tested 30 times independently, and the optimal convergence value, average value and standard deviation were calculated. 
Table 1. Benchmark functions.

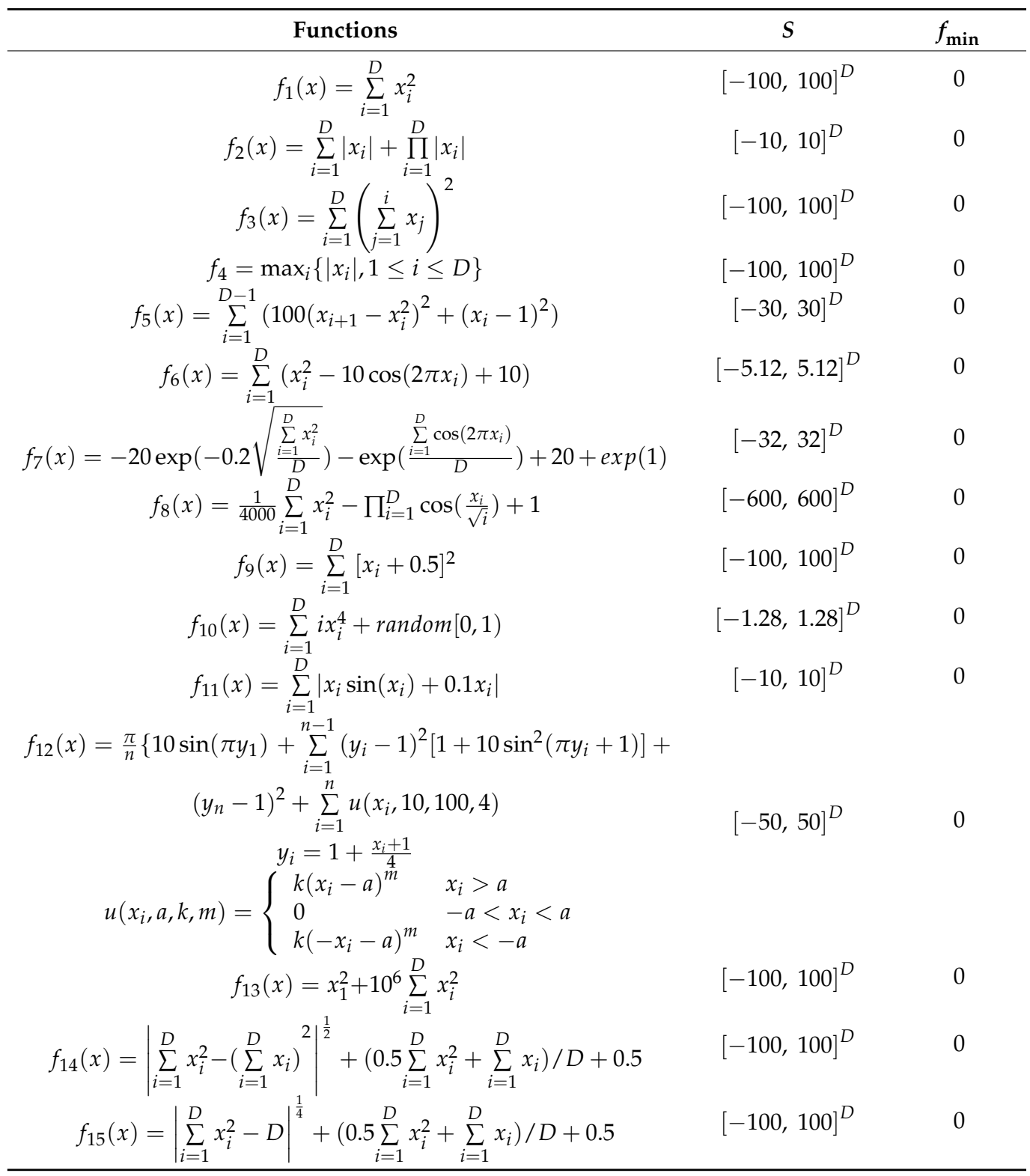

In order to understand the optimization difficulty of these test functions more clearly, the three-dimensional diagrams of these functions are shown in Figure 3.

\subsection{Parameter Settings and Experimental Environment}

In order to verify the feasibility of the CWTSSA, the SSA, DE, PSO, GWO, SSA with sine chaotic mapping strategy (CSSA), SSA with adaptive weighting strategy (WSSA), SSA with t-distribution mutation strategy (TSSA), SSA with sine chaotic mapping strategy and adaptive weighting strategy (CWSSA), SSA with sine chaotic mapping strategy and t-distribution mutation strategy (CTSSA), SSA with adaptive weighting strategy and tdistribution mutation strategy (WTSSA) are selected here. In addition, 15 test functions are used to analyze and verify the optimization results of the three strategies and the SSA. The experimental parameters of each algorithm are shown in Table 2. The experimental environment comprised an Intel(R) Core(TM) i7-7700 CPU @ 3.6GHz with 8G RAM, Windows, and the algorithm was coded in MATLAB 2019b. 

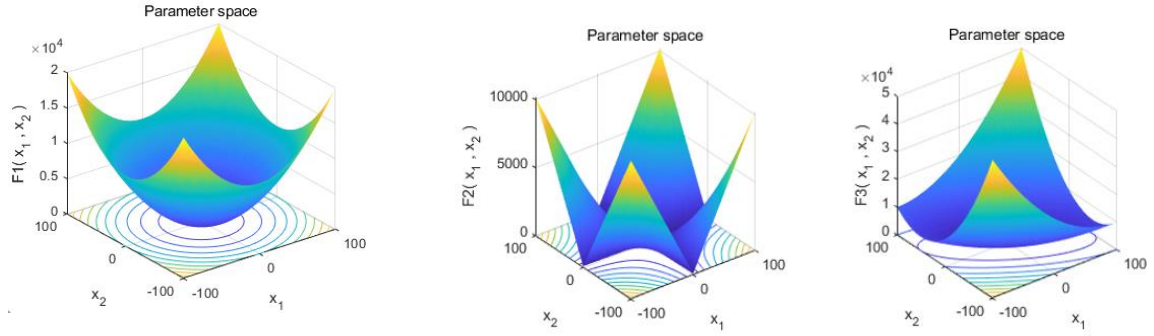

(a) $f_{1}$

(b) $f_{2}$

(c) $f_{3}$
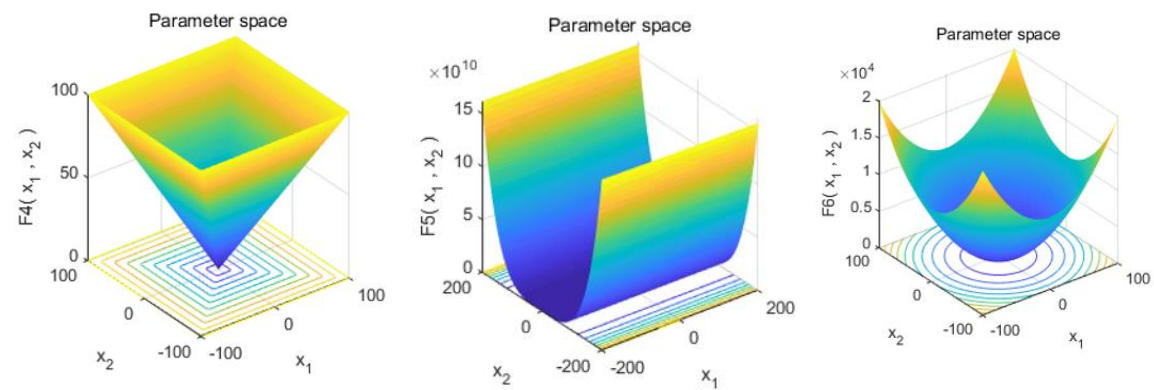

(d) $f_{4}$

(e) $f_{5}$

(f) $f_{6}$
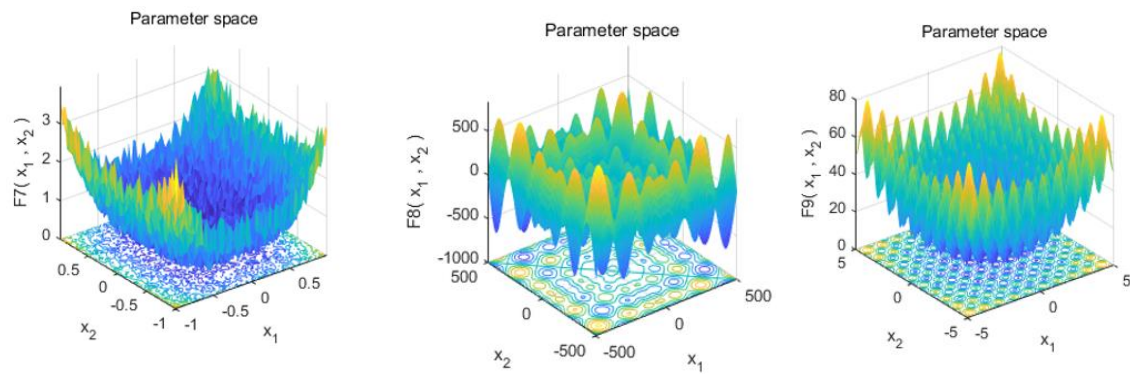

(g) $f_{7}$

(h) $f_{8}$

(i) $f_{9}$
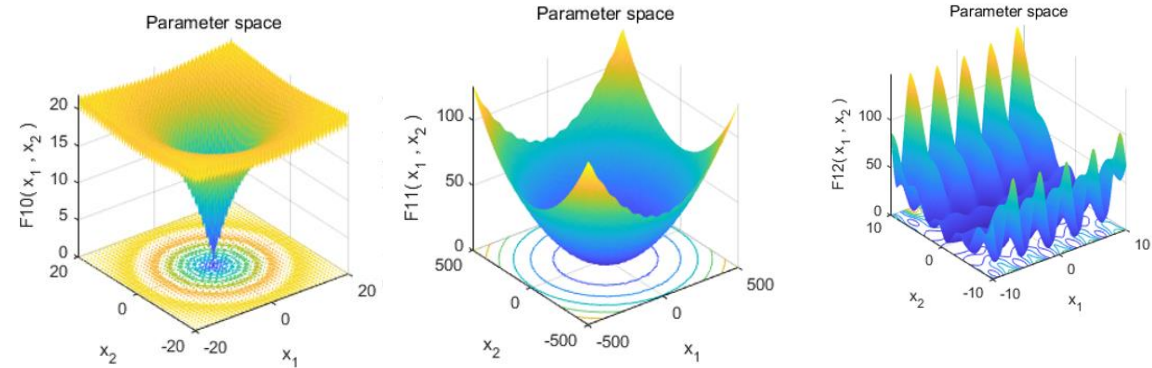

(j) $f_{10}$

(k) $f_{11}$

(l) $f_{12}$
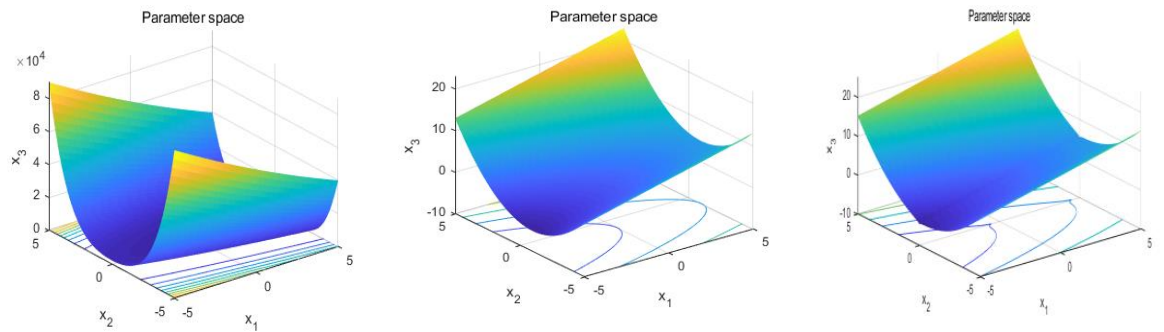

(m) $f_{13}$

(n) $f_{14}$

(o) $f_{15}$

Figure 3. Three-dimensional diagrams of the test functions. 
Table 2. Parameter settings for each algorithm.

\begin{tabular}{cc}
\hline Algorithms & Parameter Settings \\
\hline GWO & Decreases linearly from 2 to $0, r_{1}, r_{2} \in[0,1]$ \\
\hline PSO & $v_{i}=6, \omega_{\max }=0.9, \omega_{\min }=0.2, c_{1}=c_{2}=2$ \\
\hline DE & $C_{R}=0.9$ \\
\hline SSA $\backslash \mathrm{CSSA} \backslash$ WSSA $\backslash$ TSSA $\backslash$ CWSSA $\backslash \mathrm{CTSS} \backslash$ WTSSA & $P D=0.7, S D=0.2, S T=0.6$ \\
\hline
\end{tabular}

\subsection{Experimental Results and Analysis}

\subsubsection{SSA with Different Strategies}

In order to analyze each strategy clearly, three strategies are introduced into the SSA for solving 15 benchmark functions. The evaluation indexes of optimization performance include optimal value, mean value and standard deviation (Std.Dev) in order to prove the effectiveness of the proposed algorithm. The experimental results are shown in Table 3.

Table 3. Comparison results of the SSA with different strategies.

\begin{tabular}{|c|c|c|c|c|}
\hline Functions & Algorithms & Optimal Value & Mean Value & Std.Dev \\
\hline \multirow{8}{*}{$f_{1}$} & SSA & $0.0000 \mathrm{E}+00$ & $-1.1800 \mathrm{E}-246$ & $0.0000 \mathrm{E}+00$ \\
\hline & CSSA & $0.0000 \mathrm{E}+00$ & $-8.2624 \mathrm{E}-209$ & $0.0000 \mathrm{E}+00$ \\
\hline & WSSA & $5.3328 \mathrm{E}-165$ & $-6.0757 \mathrm{E}-84$ & $1.2071 \mathrm{E}-83$ \\
\hline & TSSA & $0.0000 \mathrm{E}+00$ & $1.3301 \mathrm{E}-182$ & $0.0000 \mathrm{E}+00$ \\
\hline & CWSSA & $4.8142 \mathrm{E}-44$ & $3.7280 \mathrm{E}-24$ & $4.0567 \mathrm{E}-23$ \\
\hline & CTSSA & $0.0000 \mathrm{E}+00$ & $0.0000 \mathrm{E}+00$ & $0.0000 \mathrm{E}+00$ \\
\hline & WTSSA & $0.0000 \mathrm{E}+00$ & $0.0000 \mathrm{E}+00$ & $0.0000 \mathrm{E}+00$ \\
\hline & CWTSSA & $0.0000 \mathrm{E}+00$ & $0.0000 \mathrm{E}+00$ & $0.0000 \mathrm{E}+00$ \\
\hline \multirow{8}{*}{$f_{2}$} & SSA & $0.0000 \mathrm{E}+00$ & $0.0000 \mathrm{E}+00$ & $0.0000 \mathrm{E}+00$ \\
\hline & CSSA & $0.0000 \mathrm{E}+00$ & $0.0000 \mathrm{E}+00$ & $0.0000 \mathrm{E}+00$ \\
\hline & WSSA & $5.1891 \mathrm{E}-220$ & $8.7820 \mathrm{E}-222$ & $0.0000 \mathrm{E}+00$ \\
\hline & TSSA & $0.0000 \mathrm{E}+00$ & $0.0000 \mathrm{E}+00$ & $0.0000 \mathrm{E}+00$ \\
\hline & CWSSA & $2.2862 \mathrm{E}-10$ & $5.1022 \mathrm{E}-12$ & $2.5566 \mathrm{E}-11$ \\
\hline & CTSSA & $0.0000 \mathrm{E}+00$ & $0.0000 \mathrm{E}+00$ & $0.0000 \mathrm{E}+00$ \\
\hline & WTSSA & $0.0000 \mathrm{E}+00$ & $0.0000 \mathrm{E}+00$ & $0.0000 \mathrm{E}+00$ \\
\hline & CWTSSA & $0.0000 \mathrm{E}+00$ & $0.0000 \mathrm{E}+00$ & $0.0000 \mathrm{E}+00$ \\
\hline \multirow{8}{*}{$f_{3}$} & SSA & $0.0000 \mathrm{E}+00$ & $3.4758 \mathrm{E}-171$ & $0.0000 \mathrm{E}+00$ \\
\hline & CSSA & $0.0000 \mathrm{E}+00$ & $3.4785 \mathrm{E}-237$ & $0.0000 \mathrm{E}+00$ \\
\hline & WSSA & $1.0848 \mathrm{E}-173$ & $2.1891 \mathrm{E}-89$ & $5.8870 \mathrm{E}-88$ \\
\hline & TSSA & $0.0000 \mathrm{E}+00$ & $-3.4143 \mathrm{E}-165$ & $0.0000 \mathrm{E}+00$ \\
\hline & CWSSA & $5.6884 \mathrm{E}-09$ & $-7.8547 \mathrm{E}-08$ & $2.6252 \mathrm{E}-05$ \\
\hline & CTSSA & $0.0000 \mathrm{E}+00$ & $3.0491 \mathrm{E}-168$ & $0.0000 \mathrm{E}+00$ \\
\hline & WTSSA & $0.0000 \mathrm{E}+00$ & $5.2493 \mathrm{E}-211$ & $0.0000 \mathrm{E}+00$ \\
\hline & CWTSSA & $0.0000 \mathrm{E}+00$ & $2.1387 \mathrm{E}-195$ & $0.0000 \mathrm{E}+00$ \\
\hline \multirow{8}{*}{$f_{4}$} & SSA & $0.0000 \mathrm{E}+00$ & $3.4758 \mathrm{E}-171$ & $0.0000 \mathrm{E}+00$ \\
\hline & CSSA & $0.0000 \mathrm{E}+00$ & $0.0000 \mathrm{E}+00$ & $0.0000 \mathrm{E}+00$ \\
\hline & WSSA & $7.1761 \mathrm{E}-69$ & $-5.4623 \mathrm{E}-71$ & $2.9230 \mathrm{E}-69$ \\
\hline & TSSA & $0.0000 \mathrm{E}+00$ & $0.0000 \mathrm{E}+00$ & $0.0000 \mathrm{E}+00$ \\
\hline & CWSSA & $2.1638 \mathrm{E}-05$ & $3.4421 \mathrm{E}-07$ & $1.6619 \mathrm{E}-05$ \\
\hline & CTSSA & $0.0000 \mathrm{E}+00$ & $0.0000 \mathrm{E}+00$ & $0.0000 \mathrm{E}+00$ \\
\hline & WTSSA & $0.0000 \mathrm{E}+00$ & $0.0000 \mathrm{E}+00$ & $0.0000 \mathrm{E}+00$ \\
\hline & CWTSSA & $0.0000 \mathrm{E}+00$ & $0.0000 \mathrm{E}+00$ & $0.0000 \mathrm{E}+00$ \\
\hline
\end{tabular}


Table 3. Cont.

\begin{tabular}{|c|c|c|c|c|}
\hline Functions & Algorithms & Optimal Value & Mean Value & Std.Dev \\
\hline \multirow{8}{*}{$f_{5}$} & SSA & $2.3569 \mathrm{E}-07$ & $1.0000 \mathrm{E}+00$ & $1.5551 \mathrm{E}-04$ \\
\hline & CSSA & $6.5956 \mathrm{E}-09$ & $1.0000 \mathrm{E}+00$ & $1.4077 \mathrm{E}-05$ \\
\hline & WSSA & $9.1926 \mathrm{E}-08$ & $1.0000 \mathrm{E}+00$ & $4.3810 \mathrm{E}-05$ \\
\hline & TSSA & $9.6663 \mathrm{E}-10$ & $1.0000 \mathrm{E}+00$ & $2.7537 \mathrm{E}-06$ \\
\hline & CWSSA & $4.9007 \mathrm{E}-10$ & $1.0000 \mathrm{E}+00$ & $7.7839 \mathrm{E}-06$ \\
\hline & CTSSA & $3.7843 \mathrm{E}-09$ & $9.9999 \mathrm{E}-01$ & $1.7175 \mathrm{E}-05$ \\
\hline & WTSSA & $1.0968 \mathrm{E}-07$ & $1.0000 \mathrm{E}+00$ & 8.3877E-05 \\
\hline & CWTSSA & $1.9196 \mathrm{E}-10$ & $1.0000 \mathrm{E}+00$ & $8.1964 \mathrm{E}-07$ \\
\hline \multirow{8}{*}{$f_{6}$} & SSA & $0.0000 \mathrm{E}+00$ & $-8.2921 \mathrm{E}-85$ & $1.5647 \mathrm{E}-04$ \\
\hline & CSSA & $0.0000 \mathrm{E}+00$ & $-1.8452 \mathrm{E}-12$ & $2.5029 \mathrm{E}-12$ \\
\hline & WSSA & $0.0000 \mathrm{E}+00$ & $-1.5465 \mathrm{E}-09$ & $2.1184 \mathrm{E}-09$ \\
\hline & TSSA & $0.0000 \mathrm{E}+00$ & $-1.7196 \mathrm{E}-14$ & $8.7606 \mathrm{E}-14$ \\
\hline & CWSSA & $3.4106 \mathrm{E}-13$ & $-4.0845 \mathrm{E}-10$ & $9.8165 \mathrm{E}-09$ \\
\hline & CTSSA & $0.0000 \mathrm{E}+00$ & $4.3857 \mathrm{E}-10$ & $1.2975 \mathrm{E}-10$ \\
\hline & WTSSA & $0.0000 \mathrm{E}+00$ & $-1.4131 \mathrm{E}-257$ & $0.0000 \mathrm{E}+00$ \\
\hline & CWTSSA & $2.9143 \mathrm{E}-29$ & $0.0000 \mathrm{E}+00$ & $-9.9277 E-29$ \\
\hline \multirow{8}{*}{$f_{7}$} & SSA & $8.8818 \mathrm{E}-16$ & $-1.2324 \mathrm{E}-17$ & $1.6261 \mathrm{E}-16$ \\
\hline & CSSA & $8.8818 \mathrm{E}-16$ & $3.1663 \mathrm{E}-22$ & $1.4913 \mathrm{E}-20$ \\
\hline & WSSA & $8.8818 \mathrm{E}-16$ & $6.2863 \mathrm{E}-18$ & $1.1628 \mathrm{E}-17$ \\
\hline & TSSA & $8.8818 \mathrm{E}-16$ & $-6.1321 \mathrm{E}-35$ & $2.4592 \mathrm{E}-35$ \\
\hline & CWSSA & $1.8208 \mathrm{E}-13$ & $2.7480 \mathrm{E}-16$ & $4.6383 \mathrm{E}-14$ \\
\hline & CTSSA & $8.8818 \mathrm{E}-16$ & $1.6272 \mathrm{E}-35$ & $1.8625 \mathrm{E}-33$ \\
\hline & WTSSA & $8.8818 \mathrm{E}-16$ & $4.8283 \mathrm{E}-23$ & $1.8048 \mathrm{E}-23$ \\
\hline & CWTSSA & $8.8818 \mathrm{E}-16$ & $-2.2848 \mathrm{E}-27$ & $1.4866 \mathrm{E}-27$ \\
\hline \multirow{8}{*}{$f_{8}$} & SSA & $0.0000 \mathrm{E}+00$ & $1.1311 \mathrm{E}-08$ & $8.8895 \mathrm{E}-09$ \\
\hline & CSSA & $0.0000 \mathrm{E}+00$ & $-4.6363 \mathrm{E}-10$ & $2.3686 \mathrm{E}-10$ \\
\hline & WSSA & $0.0000 \mathrm{E}+00$ & $1.3838 \mathrm{E}-09$ & $3.5495 \mathrm{E}-09$ \\
\hline & TSSA & $0.0000 \mathrm{E}+00$ & $8.4334 \mathrm{E}-10$ & $6.8132 \mathrm{E}-11$ \\
\hline & CWSSA & $1.6653 \mathrm{E}-15$ & $7.0242 \mathrm{E}-09$ & $5.2950 \mathrm{E}-08$ \\
\hline & CTSSA & $0.0000 \mathrm{E}+00$ & $1.3448 \mathrm{E}-11$ & $3.4762 \mathrm{E}-13$ \\
\hline & WTSSA & $0.0000 \mathrm{E}+00$ & $-6.6918 \mathrm{E}-11$ & $1.6768 \mathrm{E}-09$ \\
\hline & CWTSSA & $-4.5789 \mathrm{E}-09$ & $1.1029 \mathrm{E}-08$ & $0.0000 \mathrm{E}+00$ \\
\hline \multirow{8}{*}{$f_{9}$} & SSA & $1.4075 \mathrm{E}-06$ & $9.9999 \mathrm{E}-01$ & $2.6186 \mathrm{E}-05$ \\
\hline & CSSA & $1.7821 \mathrm{E}-12$ & $-5.0000 \mathrm{E}-01$ & $2.4789 \mathrm{E}-07$ \\
\hline & WSSA & $5.7779 \mathrm{E}-13$ & $-5.0000 \mathrm{E}-01$ & $1.4093 \mathrm{E}-07$ \\
\hline & TSSA & $1.2601 \mathrm{E}-13$ & $-5.0000 \mathrm{E}-01$ & $6.5678 \mathrm{E}-08$ \\
\hline & CWSSA & $0.0000 \mathrm{E}+00$ & $-5.0000 \mathrm{E}-01$ & $0.0000 \mathrm{E}+00$ \\
\hline & CTSSA & $8.8094 \mathrm{E}-13$ & $-5.0000 \mathrm{E}-01$ & $1.7428 \mathrm{E}-07$ \\
\hline & WTSSA & $4.2809 \mathrm{E}-13$ & $-5.0000 \mathrm{E}-01$ & $1.2147 \mathrm{E}-07$ \\
\hline & CWTSSA & $2.8573 \mathrm{E}-08$ & $1.0000 \mathrm{E}+00$ & $2.9451 \mathrm{E}-09$ \\
\hline \multirow{8}{*}{$f_{10}$} & SSA & $4.4249 \mathrm{E}-03$ & $-5.6627 \mathrm{E}-03$ & $1.1520 \mathrm{E}-02$ \\
\hline & CSSA & $1.0954 \mathrm{E}-04$ & $-8.0377 \mathrm{E}-03$ & $8.7378 \mathrm{E}-03$ \\
\hline & WSSA & $2.0564 \mathrm{E}-04$ & $1.1610 \mathrm{E}-02$ & $3.4126 \mathrm{E}-03$ \\
\hline & TSSA & $3.7776 \mathrm{E}-05$ & $-7.4725 \mathrm{E}-05$ & $1.4259 \mathrm{E}-04$ \\
\hline & CWSSA & $3.3013 \mathrm{E}-05$ & $-1.2963 \mathrm{E}-02$ & $5.3654 \mathrm{E}-03$ \\
\hline & CTSSA & $1.1667 \mathrm{E}-05$ & $-6.6750 \mathrm{E}-03$ & $1.0185 \mathrm{E}-09$ \\
\hline & WTSSA & $1.1592 \mathrm{E}-05$ & $9.4308 \mathrm{E}-04$ & $1.0392 \mathrm{E}-03$ \\
\hline & CWTSSA & 8.1927E-05 & $6.2220 \mathrm{E}-04$ & $9.0667 \mathrm{E}-06$ \\
\hline \multirow{8}{*}{$f_{11}$} & SSA & $-1.1346 \mathrm{E}+04$ & $3.8017 \mathrm{E}+02$ & $9.5594 \mathrm{E}+01$ \\
\hline & CSSA & $-1.2352 \mathrm{E}+04$ & $4.1373 \mathrm{E}+02$ & $3.9647 \mathrm{E}+01$ \\
\hline & WSSA & $-1.1029 \mathrm{E}+04$ & $3.6790 \mathrm{E}+02$ & $1.2627 \mathrm{E}+02$ \\
\hline & TSSA & $-1.2569 \mathrm{E}+04$ & $4.2097 \mathrm{E}+02$ & $4.4231 \mathrm{E}-05$ \\
\hline & CWSSA & $-1.1227 \mathrm{E}+04$ & $3.7618 \mathrm{E}+02$ & $1.1926 \mathrm{E}+02$ \\
\hline & CTSSA & $-1.2569 \mathrm{E}+04$ & $4.2097 \mathrm{E}+02$ & $6.1430 \mathrm{E}-03$ \\
\hline & WTSSA & $-1.2569 \mathrm{E}+04$ & $4.2097 \mathrm{E}+02$ & $1.3097 \mathrm{E}-04$ \\
\hline & CWTSSA & $3.7777 \mathrm{E}+02$ & $1.4866 \mathrm{E}+02$ & $-1.1879 \mathrm{E}-04$ \\
\hline
\end{tabular}


Table 3. Cont.

\begin{tabular}{|c|c|c|c|c|}
\hline Functions & Algorithms & Optimal Value & Mean Value & Std.Dev \\
\hline \multirow{8}{*}{$f_{12}$} & SSA & $6.9451 \mathrm{E}-05$ & $4.9734 \mathrm{E}-05$ & $3.9537 \mathrm{E}-08$ \\
\hline & CSSA & $4.6432 \mathrm{E}-13$ & $-1.0000 \mathrm{E}+00$ & $1.5557 \mathrm{E}-06$ \\
\hline & WSSA & $4.3067 \mathrm{E}-10$ & $-1.0000 \mathrm{E}+00$ & $4.7613 \mathrm{E}-05$ \\
\hline & TSSA & $6.2419 \mathrm{E}-12$ & $-1.0000 \mathrm{E}+00$ & $5.6778 \mathrm{E}-06$ \\
\hline & CWSSA & $1.6996 \mathrm{E}-32$ & $-1.0000 \mathrm{E}+00$ & $8.2465 \mathrm{E}-17$ \\
\hline & CTSSA & $7.2381 \mathrm{E}-12$ & $-1.0000 \mathrm{E}+00$ & $6.1476 \mathrm{E}-06$ \\
\hline & WTSSA & $2.2723 \mathrm{E}-12$ & $-1.0000 \mathrm{E}+00$ & $3.4413 \mathrm{E}-06$ \\
\hline & CWTSSA & 7.1167E-09 & $-9.9998 \mathrm{E}-01$ & $1.9048 \mathrm{E}-04$ \\
\hline \multirow{8}{*}{$f_{13}$} & SSA & $6.9451 \mathrm{E}-05$ & $4.9734 \mathrm{E}-05$ & $3.9537 E-08$ \\
\hline & CSSA & $1.0023 \mathrm{E}-05$ & $1.0000 \mathrm{E}+00$ & $4.3812 \mathrm{E}-09$ \\
\hline & WSSA & $8.0951 E-05$ & $1.0000 \mathrm{E}+00$ & $3.1108 \mathrm{E}-07$ \\
\hline & TSSA & $2.2859 \mathrm{E}-05$ & $1.0000 \mathrm{E}+00$ & $9.3112 \mathrm{E}-08$ \\
\hline & CWSSA & $2.8343 \mathrm{E}-06$ & $1.0000 \mathrm{E}+00$ & $8.5164 \mathrm{E}-07$ \\
\hline & CTSSA & $6.1355 \mathrm{E}-05$ & $1.0000 \mathrm{E}+00$ & $1.8308 \mathrm{E}-08$ \\
\hline & WTSSA & $9.3486 \mathrm{E}-07$ & $1.0000 \mathrm{E}+00$ & $2.4531 \mathrm{E}-08$ \\
\hline & CWTSSA & $1.6516 \mathrm{E}-05$ & $2.6485 \mathrm{E}-05$ & $1.6149 \mathrm{E}-09$ \\
\hline \multirow{10}{*}{$f_{14}$} & SSA & $0.0000 \mathrm{E}+00$ & $2.2507 \mathrm{E}-178$ & $0.0000 \mathrm{E}+00$ \\
\hline & CSSA & $0.0000 \mathrm{E}+00$ & $4.6834 \mathrm{E}-197$ & $0.0000 \mathrm{E}+00$ \\
\hline & WSSA & $0.0000 \mathrm{E}+00$ & $-5.2254 \mathrm{E}-94$ & $03.4224 \mathrm{E}-182$ \\
\hline & TSSA & $0.0000 \mathrm{E}+00$ & $0.0000 \mathrm{E}+00$ & $0.0000 \mathrm{E}+00$ \\
\hline & CWSSA & $0.0000 \mathrm{E}+00$ & $0.0000 \mathrm{E}+00$ & $0.0000 \mathrm{E}+00$ \\
\hline & CTSSA & $0.0000 \mathrm{E}+00$ & $0.0000 \mathrm{E}+00$ & $0.0000 \mathrm{E}+00$ \\
\hline & WTSSA & $0.0000 \mathrm{E}+00$ & $0.0000 \mathrm{E}+00$ & $0.0000 \mathrm{E}+00$ \\
\hline & CWTSSA & $0.0000 \mathrm{E}+00$ & $0.0000 \mathrm{E}+00$ & $0.0000 \mathrm{E}+00$ \\
\hline & CWTSSA & $0.0000 \mathrm{E}+00$ & $0.0000 \mathrm{E}+00$ & $0.0000 \mathrm{E}+00$ \\
\hline & CWISSA & $0.0000 \mathrm{E}+00$ & $0.0000 \mathrm{E}+00$ & $0.0000 \mathrm{E}+00$ \\
\hline \multirow{9}{*}{$f_{15}$} & SSA & $0.0000 \mathrm{E}+00$ & $-1.7863 \mathrm{E}-138$ & $0.0000 \mathrm{E}+00$ \\
\hline & CSSA & $0.0000 \mathrm{E}+00$ & $1.1245 \mathrm{E}-165$ & $0.0000 \mathrm{E}+00$ \\
\hline & WSSA & $0.0000 \mathrm{E}+00$ & $1.3890 \mathrm{E}-140$ & $1.6568 \mathrm{E}-278$ \\
\hline & TSSA & $0.0000 \mathrm{E}+00$ & $3.0445 \mathrm{E}-180$ & $0.0000 \mathrm{E}+00$ \\
\hline & CWSSA & $0.0000 \mathrm{E}+00$ & $6.0872 E-206$ & $0.0000 \mathrm{E}+00$ \\
\hline & CTSSA & $0.0000 \mathrm{E}+00$ & $1.1566 \mathrm{E}-168$ & $0.0000 \mathrm{E}+00$ \\
\hline & WTSSA & $0.0000 \mathrm{E}+00$ & $6.4927 \mathrm{E}-199$ & $0.0000 \mathrm{E}+00$ \\
\hline & CWTSSA & $0.0000 \mathrm{E}+00$ & $5.3679 E-206$ & $0.0000 \mathrm{E}+00$ \\
\hline & CWTSSA & $0.0000 \mathrm{E}+00$ & $5.3679 E-206$ & $0.0000 \mathrm{E}+00$ \\
\hline
\end{tabular}

As can be seen from Table 3 , for unimodal functions $f_{1}-f_{4}$, whether the single strategy or combination strategy is selected, it can achieve higher convergence accuracy than the basic SSA, which has different degrees of improvement, indicating that the three used strategies for SSA are all effective. Especially for $f_{1}, f_{2}, f_{4}$, when three strategies are used at the same time for SSA (CWTSSA), the average and standard deviation are both theoretically optimal solutions. It is not difficult to find that the convergence accuracy of using the adaptive weighting strategy has been decreased, but the effect of the t-distribution mutation strategy has been improved because the t-distribution mutation operator can make full use of the current population information on the original basis. The t-distribution mutation operator gives full play to the disturbance ability, and the global optimization performance of the algorithm can be improved. Among the multimodal functions $f_{5}-f_{8}$, most of the functions perform well, and have good performance in terms of convergence accuracy and stability. Especially for the function $f_{6}$, the combination of adaptive weighting strategy and $\mathrm{t}$-distribution mutation operator shows a clear advantage. The mean value has increased by more than two hundred orders of magnitude. Moreover, it converges to the global optimal solution, which demonstrates the search flexibility of the CWTSSA and stable optimization performance. In addition, in the relatively special test function $f_{9}-f_{12}$, the overall improvement effect is mediocre. However, the SSA with different strategies has dif- 
ferent performance on different test functions. For function $f_{9}$, the combination of the sine chaotic mapping strategy and adaptive weighting strategy makes the standard deviation and the mean value obtain the theoretical optimal value. Because of the particularity of the functions, when all the strategies are used, the satisfactory result cannot be obtained. The example for function $f_{10}$ is a function with added random noise. When the domain is positive, the value range tends to positive infinity, so the function has only a global minimum. High accuracy cannot be achieved in several cases. This may be related to the limitations of the algorithm, and also related to the ability of the algorithm to optimize. Therefore, the test function also has an impact on the performance of the algorithm. For functions $f_{14}$ and $f_{15}$, CWTSSA has also achieved better results than a single strategy or combination strategy, which further illustrates the superior performance of the algorithm.

To sum up, when the three strategies are used at the same time for SSA, most of the test functions have better convergence speed and convergence accuracy, and the stability is also better. This is inseparable from the use of the three strategies. In general, the SSA with each strategy has certain improvements compared with the basic SSA.

\subsubsection{Optimization Results for Different Dimensions}

In order to further prove the optimization performance of the CWTSSA, the GWO, $\mathrm{PSO}$, and sparrow search algorithm based on Cauchy distribution and reverse learning (CASSA) are selected for comparative analysis in three different dimensions. The obtained optimal value, average value and standard deviation after 30 independent experiments are used as the evaluation index to illustrate the convergence accuracy and convergence speed of the CWTSSA. The comparison results of five different algorithms under 30, 50, and 100 dimensions are shown in Table 4.

It can be seen from Table 4 that for simple unimodal functions, the CWTSSA and DE, GWO, PSO, SSA, CASSA have achieved better optimization results, and they do not cause great obstacles with the increase in dimensionality. The CWTSSA performs well, and can even converge to the global optimal value under the different dimensions. However, for more complex multimodal functions $f_{5}-f_{8}$, the increased dimensionality greatly increases the difficulty and weakens the optimization performance of all algorithms. It can also be seen that the convergence accuracy of the CWTSSA has been improved, and the standard deviation is kept at a small value. The experimental results show that the stability of the CWTSSA is stronger than that of the other compared algorithms. For $f_{13}, f_{14}$, the CWTSSA algorithm performs well by in comparison with other algorithms, which fully illustrates the increased necessity of the strategy. From the perspective of horizontal comparison, the solution accuracy of the CWTSSA has not been reduced by the gradual increase in dimensionality. The experimental results show that the CWTSSA has withstood the test of increases in dimensionality. 
Table 4. The comparison results of five algorithms under $\mathrm{D}=30,50$ and 100 .

\begin{tabular}{|c|c|c|c|c|c|c|c|c|c|c|}
\hline \multirow{2}{*}{ Functions } & \multirow{2}{*}{ Algorithms } & \multicolumn{3}{|c|}{$\mathrm{D}=30$} & \multicolumn{3}{|c|}{$\mathrm{D}=\mathbf{5 0}$} & \multicolumn{3}{|c|}{$\mathrm{D}=100$} \\
\hline & & Optimal Value & Mean Value & Std. Dev & Optimal Value & Mean Value & Std. Dev & Optimal Value & Mean Value & Std. Dev \\
\hline \multirow{5}{*}{$f_{1}$} & $\mathrm{DE}$ & $1.3461 \mathrm{E}-04$ & $2.8733 \mathrm{E}-04$ & $7.1606 \mathrm{E}-09$ & $1.0268 \mathrm{E}-02$ & $1.7125 \mathrm{E}-02$ & $2.7978 \mathrm{E}-05$ & $1.0794 \mathrm{E}-02$ & $2.1340 \mathrm{E}-02$ & $4.1207 \mathrm{E}-04$ \\
\hline & GWO & $1.3600 \mathrm{E}-85$ & $9.8340 \mathrm{E}-46$ & $6.8473 \mathrm{E}-44$ & $2.1438 \mathrm{E}-63$ & $5.3030 \mathrm{E}-34$ & $6.5928 \mathrm{E}-33$ & $2.9413 \mathrm{E}-41$ & $-5.4836 \mathrm{E}-24$ & $5.4505 \mathrm{E}-22$ \\
\hline & SSA & $0.0000 \mathrm{E}+00$ & $-1.1800 \mathrm{E}-246$ & $0.0000 \mathrm{E}+00$ & $0.0000 \mathrm{E}+00$ & $1.1925 \mathrm{E}-164$ & $0.0000 \mathrm{E}+00$ & $0.0000 \mathrm{E}+00$ & $3.7884 \mathrm{E}-180$ & $0.0000 \mathrm{E}+00$ \\
\hline & CASSA & $0.0000 \mathrm{E}+00$ & $5.8842 \mathrm{E}-164$ & $0.0000 \mathrm{E}+00$ & $2.0481 E-303$ & $8.9421 \mathrm{E}-154$ & $6.4017 \mathrm{E}-153$ & $0.0000 \mathrm{E}+00$ & $-1.0269 \mathrm{E}-164$ & $0.0000 \mathrm{E}+00$ \\
\hline & CWTSSA & $0.0000 \mathrm{E}+00$ & $0.0000 \mathrm{E}+00$ & $0.0000 \mathrm{E}+00$ & $0.0000 \mathrm{E}+00$ & $4.3477 \mathrm{E}-229$ & $0.0000 \mathrm{E}+00$ & $0.0000 \mathrm{E}+00$ & $0.0000 \mathrm{E}+00$ & $0.0000 \mathrm{E}+00$ \\
\hline \multirow{6}{*}{$f_{2}$} & $\mathrm{DE}$ & $2.1713 \mathrm{E}-02$ & $4.0723 \mathrm{E}-02$ & $3.2758 \mathrm{E}-06$ & $2.5846 \mathrm{E}-02$ & $4.6104 \mathrm{E}-02$ & $5.0264 \mathrm{E}-05$ & $3.5144 \mathrm{E}-02$ & $4.6964 \mathrm{E}-02$ & $2.7525 \mathrm{E}-05$ \\
\hline & GWO & $1.5420 \mathrm{E}-48$ & $6.6672 \mathrm{E}-52$ & $5.2543 \mathrm{E}-50$ & $6.0229 \mathrm{E}-36$ & $2.6356 \mathrm{E}-39$ & $1.2277 \mathrm{E}-37$ & $1.4056 \mathrm{E}-36$ & $-3.5620 \mathrm{E}-39$ & $2.8369 \mathrm{E}-38$ \\
\hline & PSO & $1.1091 \mathrm{E}-07$ & $2.3028 \mathrm{E}-09$ & $9.2751 \mathrm{E}-09$ & $1.6165 \mathrm{E}-03$ & $1.6730 \mathrm{E}-05$ & $8.7169 \mathrm{E}-05$ & $8.1875 \mathrm{E}-03$ & $-1.3087 \mathrm{E}-04$ & $9.5439 \mathrm{E}-04$ \\
\hline & SSA & $0.0000 \mathrm{E}+00$ & $0.0000 \mathrm{E}+00$ & $0.0000 \mathrm{E}+00$ & $0.0000 \mathrm{E}+00$ & $0.0000 \mathrm{E}+00$ & $0.0000 \mathrm{E}+00$ & $0.0000 \mathrm{E}+00$ & $0.0000 \mathrm{E}+00$ & $0.0000 \mathrm{E}+00$ \\
\hline & CASSA & $2.2145 \mathrm{E}-102$ & $-7.3817 \mathrm{E}-104$ & $1.7059 \mathrm{E}-103$ & $1.0708 \mathrm{E}-67$ & $2.6641 \mathrm{E}-70$ & $3.4774 \mathrm{E}-69$ & $1.6007 \mathrm{E}-151$ & $1.7855 \mathrm{E}-154$ & $9.3784 \mathrm{E}-153$ \\
\hline & CWTSSA & $0.0000 \mathrm{E}+00$ & $0.0000 \mathrm{E}+00$ & $0.0000 \mathrm{E}+00$ & $0.0000 \mathrm{E}+00$ & $0.0000 \mathrm{E}+00$ & $0.0000 \mathrm{E}+00$ & $0.0000 \mathrm{E}+00$ & $0.0000 \mathrm{E}+00$ & $0.0000 \mathrm{E}+00$ \\
\hline \multirow{6}{*}{$f_{3}$} & $\mathrm{DE}$ & $3.8872 \mathrm{E}-10$ & $2.1354 \mathrm{E}-09$ & $1.71815 \mathrm{E}-18$ & $7.6264 \mathrm{E}-06$ & $2.6807 \mathrm{E}-05$ & $5.0914 \mathrm{E}-10$ & $7.6264 \mathrm{E}-06$ & $2.6807 \mathrm{E}-05$ & $5.0914 \mathrm{E}-10$ \\
\hline & GWO & $1.1110 \mathrm{E}-28$ & $-6.6126 \mathrm{E}-17$ & $3.1740 \mathrm{E}-15$ & $6.7645 \mathrm{E}-15$ & $1.3989 \mathrm{E}-10$ & $1.9112 \mathrm{E}-08$ & $4.0597 \mathrm{E}-04$ & $6.1519 \mathrm{E}-06$ & $2.8049 \mathrm{E}-03$ \\
\hline & PSO & $1.1244 \mathrm{E}+00$ & $-1.0827 \mathrm{E}-03$ & $3.5418 \mathrm{E}-01$ & $2.7411 \mathrm{E}+02$ & $2.5877 \mathrm{E}-02$ & $4.0249 \mathrm{E}+00$ & $4.7655 \mathrm{E}+03$ & $-8.8581 \mathrm{E}-02$ & $1.0827 \mathrm{E}+01$ \\
\hline & SSA & $0.0000 \mathrm{E}+00$ & $3.4758 \mathrm{E}-171$ & $0.0000 \mathrm{E}+00$ & $0.0000 \mathrm{E}+00$ & $-8.2955 \mathrm{E}-169$ & $0.0000 \mathrm{E}+00$ & $0.0000 \mathrm{E}+00$ & $4.8474 \mathrm{E}-246$ & $0.0000 \mathrm{E}+00$ \\
\hline & CASSA & $2.4787 \mathrm{E}-191$ & $-2.9471 \mathrm{E}-98$ & $4.9871 \mathrm{E}-97$ & $5.5755 \mathrm{E}-237$ & $-1.3824 \mathrm{E}-121$ & $5.2543 \mathrm{E}-120$ & $3.6180 \mathrm{E}-191$ & $4.7760 \mathrm{E}-99$ & $3.9848 \mathrm{E}-97$ \\
\hline & CWTSSA & $0.0000 \mathrm{E}+00$ & 2.1387E-195 & $0.0000 \mathrm{E}+00$ & $0.0000 \mathrm{E}+00$ & $6.4226 \mathrm{E}-226$ & $0.0000 \mathrm{E}+00$ & $0.0000 \mathrm{E}+00$ & $-6.1709 \mathrm{E}-170$ & $0.0000 \mathrm{E}+00$ \\
\hline \multirow{5}{*}{$f_{4}$} & GWO & $3.4932 \mathrm{E}-22$ & $7.0769 \mathrm{E}-23$ & $3.4581 \mathrm{E}-22$ & $7.1373 \mathrm{E}-15$ & $-2.6850 \mathrm{E}-16$ & $6.9964 \mathrm{E}-15$ & $9.8533 \mathrm{E}-14$ & $-7.0585 \mathrm{E}-15$ & $9.6429 \mathrm{E}-14$ \\
\hline & PSO & $2.4272 \mathrm{E}-01$ & $-1.2400 \mathrm{E}-02$ & $1.5773 \mathrm{E}-01$ & $1.4742 \mathrm{E}+00$ & $-1.3625 \mathrm{E}-01$ & $1.0022 \mathrm{E}+00$ & $1.4472 \mathrm{E}+00$ & $-1.7855 \mathrm{E}-02$ & $1.0502 \mathrm{E}+00$ \\
\hline & SSA & $0.0000 \mathrm{E}+00$ & $0.0000 \mathrm{E}+00$ & $0.0000 \mathrm{E}+00$ & $0.0000 \mathrm{E}+00$ & $0.0000 \mathrm{E}+00$ & $0.0000 \mathrm{E}+00$ & $0.0000 \mathrm{E}+00$ & $0.0000 \mathrm{E}+00$ & $0.0000 \mathrm{E}+00$ \\
\hline & CASSA & $6.2620 \mathrm{E}-167$ & $7.7757 \mathrm{E}-168$ & $0.0000 \mathrm{E}+00$ & $2.5427 \mathrm{E}-111$ & $-4.7041 \mathrm{E}-114$ & $9.2756 \mathrm{E}-112$ & $2.6810 \mathrm{E}-91$ & $-2.2492 \mathrm{E}-92$ & $1.1888 \mathrm{E}-91$ \\
\hline & CWTSSA & $0.0000 \mathrm{E}+00$ & $0.0000 \mathrm{E}+00$ & $0.0000 \mathrm{E}+00$ & $0.0000 \mathrm{E}+00$ & $0.0000 \mathrm{E}+00$ & $0.0000 \mathrm{E}+00$ & $0.0000 \mathrm{E}+00$ & $0.0000 \mathrm{E}+00$ & $0.0000 \mathrm{E}+00$ \\
\hline \multirow{6}{*}{$f_{5}$} & $\mathrm{DE}$ & $6.2588 \mathrm{E}-07$ & $2.5103 \mathrm{E}-06$ & $2.2725 \mathrm{E}-12$ & $1.3052 \mathrm{E}-01$ & $2.4193 \mathrm{E}-01$ & $4.0741 \mathrm{E}-03$ & $1.1908 \mathrm{E}-01$ & $2.3538 \mathrm{E}-01$ & $3.7345 \mathrm{E}-03$ \\
\hline & GWO & $2.6206 \mathrm{E}+01$ & 7.4021E-02 & $2.0834 \mathrm{E}-01$ & $4.6161 \mathrm{E}+01$ & $4.5030 \mathrm{E}-02$ & $1.6422 \mathrm{E}-01$ & $4.7803 \mathrm{E}+01$ & $1.8710 \mathrm{E}-02$ & $6.7198 \mathrm{E}-02$ \\
\hline & PSO & 7.0767E+01 & $1.0896 \mathrm{E}+00$ & $1.1081 \mathrm{E}+00$ & $4.9716 \mathrm{E}+01$ & $1.0770 \mathrm{E}-02$ & $1.0974 \mathrm{E}-01$ & $4.6984 \mathrm{E}+01$ & $3.4508 \mathrm{E}-02$ & $1.0345 \mathrm{E}-01$ \\
\hline & SSA & $2.3569 \mathrm{E}-07$ & $1.0000 \mathrm{E}+00$ & $1.5551 \mathrm{E}-04$ & $1.9458 \mathrm{E}-06$ & $1.0000 \mathrm{E}+00$ & $4.1439 \mathrm{E}-05$ & $7.9410 \mathrm{E}-09$ & $1.0000 \mathrm{E}+00$ & $1.5139 \mathrm{E}-06$ \\
\hline & CASSA & $8.0201 \mathrm{E}-07$ & $1.0000 \mathrm{E}+00$ & $0.0000 \mathrm{E}+00$ & $3.5811 \mathrm{E}-06$ & $1.0000 \mathrm{E}+00$ & $2.5886 \mathrm{E}-05$ & $1.1461 \mathrm{E}-07$ & $1.0000 \mathrm{E}+00$ & $1.1449 \mathrm{E}-05$ \\
\hline & CWTSSA & $1.9196 \mathrm{E}-10$ & $1.0000 \mathrm{E}+00$ & $8.1964 \mathrm{E}-07$ & $1.0064 \mathrm{E}-08$ & $1.0000 \mathrm{E}+00$ & $2.4026 \mathrm{E}-06$ & $5.5975 \mathrm{E}-08$ & $1.0000 \mathrm{E}+00$ & $4.9458 \mathrm{E}-06$ \\
\hline \multirow{6}{*}{$f_{6}$} & $\mathrm{DE}$ & $2.4648 \mathrm{E}+01$ & $2.6385 \mathrm{E}+01$ & $3.7241 \mathrm{E}-01$ & $4.7449 \mathrm{E}+01$ & $1.2788 \mathrm{E}+02$ & $2.9245 \mathrm{E}+03$ & $4.7789 \mathrm{E}+01$ & $1.0296 \mathrm{E}+02$ & $1.7396 \mathrm{E}+03$ \\
\hline & GWO & $0.0000 \mathrm{E}+00$ & $1.5410 \mathrm{E}-10$ & $4.8725 \mathrm{E}-09$ & $0.0000 \mathrm{E}+00$ & $5.5161 \mathrm{E}-10$ & $4.5388 \mathrm{E}-09$ & $5.6843 \mathrm{E}-14$ & $-3.5719 \mathrm{E}-10$ & $5.9066 \mathrm{E}-09$ \\
\hline & PSO & $1.9923 \mathrm{E}+01$ & $-2.6568 \mathrm{E}-01$ & $1.1106 \mathrm{E}+00$ & $7.0644 \mathrm{E}+01$ & $-1.9932 \mathrm{E}-02$ & $1.1975 \mathrm{E}+00$ & $1.0372 \mathrm{E}+02$ & $-9.8359 \mathrm{E}-02$ & $1.4393 \mathrm{E}+00$ \\
\hline & SSA & $0.0000 \mathrm{E}+00$ & $-8.2921 \mathrm{E}-85$ & $1.5647 \mathrm{E}-04$ & $0.0000 \mathrm{E}+00$ & $-2.9923 \mathrm{E}-20$ & $1.3238 \mathrm{E}-23$ & $0.0000 \mathrm{E}+00$ & $3.9451 \mathrm{E}-17$ & $1.2122 \mathrm{E}-15$ \\
\hline & CASSA & $0.0000 \mathrm{E}+00$ & $8.2356 \mathrm{E}-11$ & $8.1102 \mathrm{E}-05$ & $0.0000 \mathrm{E}+00$ & $-6.3165 \mathrm{E}-11$ & $2.1306 \mathrm{E}-09$ & $0.0000 \mathrm{E}+00$ & $-2.2447 \mathrm{E}-10$ & $1.0307 \mathrm{E}-09$ \\
\hline & CWTSSA & $2.9143 \mathrm{E}-29$ & $0.0000 \mathrm{E}+00$ & $-9.9277 \mathrm{E}-29$ & $0.0000 \mathrm{E}+00$ & $9.6822 \mathrm{E}-10$ & $4.7348 \mathrm{E}-10$ & $0.0000 \mathrm{E}+00$ & $1.6898 \mathrm{E}-11$ & $1.7143 \mathrm{E}-09$ \\
\hline
\end{tabular}


Table 4. Cont.

\begin{tabular}{|c|c|c|c|c|c|c|c|c|c|c|}
\hline \multirow{2}{*}{ Functions } & \multirow{2}{*}{ Algorithms } & \multicolumn{3}{|c|}{$\mathrm{D}=30$} & \multicolumn{3}{|c|}{$\mathrm{D}=50$} & \multicolumn{3}{|c|}{$D=100$} \\
\hline & & Optimal Value & Mean Value & Std. Dev & Optimal Value & Mean Value & Std. Dev & Optimal Value & Mean Value & Std. Dev \\
\hline \multirow{5}{*}{$f_{7}$} & $\mathrm{DE}$ & $3.4300 \mathrm{E}-04$ & $6.2174 \mathrm{E}-04$ & $3.17051 \mathrm{E}-08$ & $2.1696 \mathrm{E}-02$ & $4.1881 \mathrm{E}-02$ & $1.3943 \mathrm{E}-04$ & $2.3432 \mathrm{E}-02$ & $4.1560 \mathrm{E}-02$ & $1.0870 \mathrm{E}-04$ \\
\hline & GWO & $7.9936 \mathrm{E}-15$ & $4.8862 \mathrm{E}-16$ & $2.4763 \mathrm{E}-15$ & $2.2204 \mathrm{E}-14$ & $6.5033 \mathrm{E}-16$ & $5.7650 \mathrm{E}-15$ & $5.6843 \mathrm{E}-14$ & $-3.5719 \mathrm{E}-10$ & $5.9066 \mathrm{E}-09$ \\
\hline & SSA & $8.8818 \mathrm{E}-16$ & $-1.2324 \mathrm{E}-17$ & $1.6261 \mathrm{E}-16$ & $8.8818 \mathrm{E}-16$ & $4.2286 \mathrm{E}-45$ & $2.8335 \mathrm{E}-45$ & $0.0000 \mathrm{E}+00$ & $3.9451 \mathrm{E}-17$ & $1.2122 \mathrm{E}-15$ \\
\hline & CASSA & $8.8818 \mathrm{E}-16$ & $-8.7977 \mathrm{E}-17$ & $1.6220 \mathrm{E}-16$ & $8.8818 \mathrm{E}-16$ & $9.0729 \mathrm{E}-18$ & $2.7466 \mathrm{E}-16$ & $0.0000 \mathrm{E}+00$ & $-2.2447 \mathrm{E}-10$ & $1.0307 \mathrm{E}-09$ \\
\hline & CWTSSA & $8.8818 \mathrm{E}-16$ & $-2.2848 \mathrm{E}-27$ & $1.4866 \mathrm{E}-27$ & $8.8818 \mathrm{E}-16$ & $-8.6420 \mathrm{E}-21$ & $2.5338 \mathrm{E}-20$ & $0.0000 \mathrm{E}+00$ & $1.6898 \mathrm{E}-11$ & $1.7143 \mathrm{E}-09$ \\
\hline \multirow{6}{*}{$f_{8}$} & $\mathrm{DE}$ & $0.0000 \mathrm{E}+00$ & $0.0000 \mathrm{E}+00$ & $0.0000 \mathrm{E}+00$ & $2.5575 \mathrm{E}+03$ & $3.9087 \mathrm{E}+03$ & $9.0598 \mathrm{E}+05$ & $2.8941 \mathrm{E}-03$ & $4.0273 \mathrm{E}-03$ & $4.6495 \mathrm{E}-05$ \\
\hline & GWO & $0.0000 \mathrm{E}+00$ & $1.0277 \mathrm{E}-09$ & $2.4437 \mathrm{E}-08$ & $0.0000 \mathrm{E}+00$ & $-5.3324 \mathrm{E}-09$ & $1.2633 \mathrm{E}-08$ & $0.0000 \mathrm{E}+00$ & $2.5067 \mathrm{E}-09$ & $1.6144 \mathrm{E}-08$ \\
\hline & PSO & $9.8573 \mathrm{E}-03$ & $-2.8578 \mathrm{E}-01$ & $1.1285 \mathrm{E}+00$ & $2.6583 \mathrm{E}-01$ & $-3.7032 \mathrm{E}-02$ & $1.0856 \mathrm{E}+01$ & $2.1665 \mathrm{E}-01$ & $9.9227 \mathrm{E}-01$ & $9.7458 \mathrm{E}+00$ \\
\hline & SSA & $0.0000 \mathrm{E}+00$ & $1.1311 \mathrm{E}-08$ & $8.8895 \mathrm{E}-09$ & $0.0000 \mathrm{E}+00$ & $-2.0993 \mathrm{E}-11$ & $3.7487 \mathrm{E}-10$ & $0.0000 \mathrm{E}+00$ & $1.1880 \mathrm{E}-14$ & $1.7189 \mathrm{E}-18$ \\
\hline & CASSA & $0.0000 \mathrm{E}+00$ & $-3.3229 \mathrm{E}-09$ & $1.5808 \mathrm{E}-08$ & $0.0000 \mathrm{E}+00$ & $-2.4665 \mathrm{E}-11$ & $7.9290 \mathrm{E}-10$ & $0.0000 \mathrm{E}+00$ & $2.5306 \mathrm{E}-09$ & $1.1744 \mathrm{E}-08$ \\
\hline & CWTSSA & $-4.5789 \mathrm{E}-09$ & $1.1029 \mathrm{E}-08$ & $0.0000 \mathrm{E}+00$ & $0.0000 \mathrm{E}+00$ & $1.0913 \mathrm{E}-214$ & $0.0000 \mathrm{E}+00$ & $0.0000 \mathrm{E}+00$ & $-1.9912 \mathrm{E}-11$ & $5.3471 \mathrm{E}-13$ \\
\hline \multirow{6}{*}{$f_{9}$} & $\mathrm{DE}$ & $1.9059 \mathrm{E}+01$ & $7.7185 \mathrm{E}+01$ & $2.2635 \mathrm{E}+03$ & $0.0000 \mathrm{E}+00$ & $2.3333 \mathrm{E}-01$ & $1.7889 \mathrm{E}-01$ & $2.1204 \mathrm{E}-03$ & $7.1654 \mathrm{E}-03$ & $2.1204 \mathrm{E}-03$ \\
\hline & GWO & $2.6233 \mathrm{E}+01$ & $7.3219 \mathrm{E}-02$ & $2.0598 \mathrm{E}-01$ & $9.9879 \mathrm{E}-01$ & $-4.5999 \mathrm{E}-01$ & $1.3693 \mathrm{E}-01$ & $1.5011 \mathrm{E}+00$ & $-4.4001 \mathrm{E}-01$ & $1.6420 \mathrm{E}-01$ \\
\hline & PSO & $2.3915 \mathrm{E}+01$ & $1.3789 \mathrm{E}-01$ & $2.8668 \mathrm{E}-01$ & $2.8194 \mathrm{E}-07$ & $-4.9999 \mathrm{E}-01$ & $7.5618 \mathrm{E}-05$ & $2.1605 \mathrm{E}-07$ & $-5.0000 \mathrm{E}-01$ & $6.6319 \mathrm{E}-05$ \\
\hline & SSA & $1.4075 \mathrm{E}-06$ & $9.9999 \mathrm{E}-01$ & $2.6186 \mathrm{E}-05$ & $1.4923 \mathrm{E}-12$ & $-5.0000 \mathrm{E}-01$ & $1.7450 \mathrm{E}-07$ & $3.1120 \mathrm{E}-11$ & $-5.0000 \mathrm{E}-01$ & $7.9593 \mathrm{E}-07$ \\
\hline & CASSA & $6.3910 \mathrm{E}-08$ & $1.0000 \mathrm{E}+00$ & $5.5892 \mathrm{E}-05$ & $4.0322 \mathrm{E}-10$ & $-5.0000 \mathrm{E}-01$ & $2.8686 \mathrm{E}-06$ & $2.4162 \mathrm{E}-10$ & $-5.0000 \mathrm{E}-01$ & $2.2099 \mathrm{E}-06$ \\
\hline & CWTSSA & $2.8573 \mathrm{E}-08$ & $1.0000 \mathrm{E}+00$ & $2.9451 \mathrm{E}-09$ & $3.1424 \mathrm{E}-12$ & $-5.0000 \mathrm{E}-01$ & $2.5324 \mathrm{E}-07$ & $3.2117 \mathrm{E}-13$ & $-5.0000 \mathrm{E}-01$ & $8.0958 \mathrm{E}-08$ \\
\hline \multirow{5}{*}{$f_{10}$} & GWO & $2.7025 \mathrm{E}-04$ & $-1.5746 \mathrm{E}-03$ & $2.4657 \mathrm{E}-02$ & $2.0715 \mathrm{E}-04$ & $-1.0733 \mathrm{E}-03$ & $1.5667 \mathrm{E}-02$ & $1.1696 \mathrm{E}-03$ & $1.5788 \mathrm{E}-03$ & $2.6007 \mathrm{E}-02$ \\
\hline & PSO & $4.5284 \mathrm{E}-02$ & $9.3585 \mathrm{E}-03$ & $8.4315 \mathrm{E}-02$ & $2.0582 \mathrm{E}-01$ & $3.4127 \mathrm{E}-03$ & $1.1502 \mathrm{E}-01$ & $1.0324 \mathrm{E}-01$ & $-4.7509 \mathrm{E}-03$ & $9.0507 \mathrm{E}-02$ \\
\hline & SSA & $4.4249 \mathrm{E}-03$ & $-5.6627 \mathrm{E}-03$ & $1.1520 \mathrm{E}-02$ & $2.9545 \mathrm{E}-06$ & $2.2151 \mathrm{E}-03$ & $2.0804 \mathrm{E}-03$ & $3.8764 \mathrm{E}-05$ & $1.9316 \mathrm{E}-03$ & $7.3968 \mathrm{E}-03$ \\
\hline & CASSA & $1.0524 \mathrm{E}-04$ & $4.7105 \mathrm{E}-03$ & $1.3418 \mathrm{E}-02$ & $9.4250 \mathrm{E}-05$ & $1.1618 \mathrm{E}-02$ & $5.9542 \mathrm{E}-03$ & $2.2637 \mathrm{E}-05$ & $8.0122 \mathrm{E}-03$ & $3.5331 \mathrm{E}-03$ \\
\hline & CWTSSA & $8.1927 \mathrm{E}-05$ & $6.2220 \mathrm{E}-04$ & $9.0667 \mathrm{E}-06$ & $1.4317 \mathrm{E}-05$ & $1.8811 \mathrm{E}-04$ & 4.7093E-04 & $7.4629 \mathrm{E}-06$ & $6.2317 \mathrm{E}-03$ & $2.4261 \mathrm{E}-03$ \\
\hline \multirow{6}{*}{$f_{11}$} & $\mathrm{DE}$ & $2.7118 \mathrm{E}+07$ & $1.2272 \mathrm{E}+06$ & $4.65509 \mathrm{E}+13$ & $7.6019 \mathrm{E}+01$ & $8.5498 \mathrm{E}+01$ & $1.6249 \mathrm{E}+01$ & $0.0000 \mathrm{E}+00$ & $3.6667 \mathrm{E}-01$ & $2.9889 \mathrm{E}-01$ \\
\hline & GWO & $-7.4177 \mathrm{E}+03$ & $3.0557 \mathrm{E}+01$ & $2.9776 \mathrm{E}+02$ & $1.1181 \mathrm{E}+04$ & $8.9578 \mathrm{E}+01$ & $2.7065 \mathrm{E}+02$ & $-1.0070 \mathrm{E}+04$ & $1.1032 \mathrm{E}+02$ & $2.3762 \mathrm{E}+02$ \\
\hline & PSO & $-7.3971 \mathrm{E}+03$ & $-6.7431 E+01$ & $2.7579 \mathrm{E}+02$ & $-1.3921 \mathrm{E}+04$ & $4.9988 \mathrm{E}+01$ & $3.1822 \mathrm{E}+02$ & $-1.3012 \mathrm{E}+04$ & $4.9680 \mathrm{E}+01$ & $2.9187 \mathrm{E}+02$ \\
\hline & SSA & $-1.1346 \mathrm{E}+04$ & $3.8017 \mathrm{E}+02$ & $9.5594 \mathrm{E}+01$ & $-2.0160 \mathrm{E}+04$ & $4.0517 \mathrm{E}+02$ & $6.5182 \mathrm{E}+01$ & $-1.9606 \mathrm{E}+04$ & $3.9409 \mathrm{E}+02$ & $9.4386 \mathrm{E}+01$ \\
\hline & CASSA & $-1.1918 \mathrm{E}+04$ & $3.9925 \mathrm{E}+02$ & $6.6204 \mathrm{E}+01$ & $-2.0731 \mathrm{E}+04$ & $4.1662 \mathrm{E}+02$ & $3.0694 \mathrm{E}+01$ & $-1.8803 E+04$ & $3.6040 \mathrm{E}+02$ & $1.5116 \mathrm{E}+02$ \\
\hline & CWTSSA & $3.7777 \mathrm{E}+02$ & $1.4866 \mathrm{E}+02$ & $-1.1879 \mathrm{E}-04$ & $-2.0949 \mathrm{E}+04$ & $4.2097 \mathrm{E}+02$ & $5.1097 \mathrm{E}-04$ & $-2.0534 \mathrm{E}+04$ & $4.1265 \mathrm{E}+02$ & $5.8793 \mathrm{E}+01$ \\
\hline \multirow{6}{*}{$f_{12}$} & $\mathrm{DE}$ & $1.9323 \mathrm{E}-10$ & $-9.0024 \mathrm{E}-01$ & $5.0927 \mathrm{E}-05$ & $4.5748 \mathrm{E}-25$ & $2.1325 \mathrm{E}-16$ & $3.4507 \mathrm{E}-31$ & $1.7760 \mathrm{E}-26$ & $9.2253 \mathrm{E}-14$ & $1.0726 \mathrm{E}-25$ \\
\hline & GWO & $4.3146 \mathrm{E}-05$ & $-9.9740 \mathrm{E}-01$ & $1.4729 \mathrm{E}-02$ & $2.7187 \mathrm{E}-02$ & $-8.5340 \mathrm{E}-01$ & $3.4545 \mathrm{E}-01$ & $4.1277 \mathrm{E}-02$ & $-7.8656 \mathrm{E}-01$ & $4.0989 \mathrm{E}-01$ \\
\hline & PSO & $3.0908 \mathrm{E}-09$ & $-1.0000 \mathrm{E}+00$ & $1.2667 \mathrm{E}-04$ & $1.5054 \mathrm{E}-09$ & $-9.9999 \mathrm{E}-01$ & $8.7237 \mathrm{E}-05$ & $7.9515 \mathrm{E}-10$ & $-9.9999 \mathrm{E}-01$ & $6.3920 \mathrm{E}-05$ \\
\hline & SSA & $1.9323 \mathrm{E}-02$ & $-6.3419 \mathrm{E}-01$ & $2.3640 \mathrm{E}-01$ & $2.2212 \mathrm{E}-10$ & $-1.0000 \mathrm{E}+00$ & $3.3853 \mathrm{E}-05$ & $2.6260 \mathrm{E}-14$ & $-1.0000 \mathrm{E}+00$ & $3.6868 \mathrm{E}-07$ \\
\hline & CASSA & $4.9932 \mathrm{E}-10$ & $-1.0000 \mathrm{E}+00$ & $2.9462 \mathrm{E}-05$ & $2.0897 \mathrm{E}-09$ & $-1.0000 \mathrm{E}+00$ & $1.0384 \mathrm{E}-04$ & $6.4540 \mathrm{E}-10$ & $-1.0000 \mathrm{E}+00$ & $5.7769 \mathrm{E}-05$ \\
\hline & CWTSSA & $7.1167 \mathrm{E}-09$ & $-9.9998 \mathrm{E}-01$ & $1.9048 \mathrm{E}-04$ & $4.6788 \mathrm{E}-11$ & $-1.0000 \mathrm{E}+00$ & $1.5581 \mathrm{E}-05$ & $2.9084 \mathrm{E}-15$ & $-1.0000 \mathrm{E}+00$ & $1.2245 \mathrm{E}-07$ \\
\hline
\end{tabular}


Table 4. Cont.

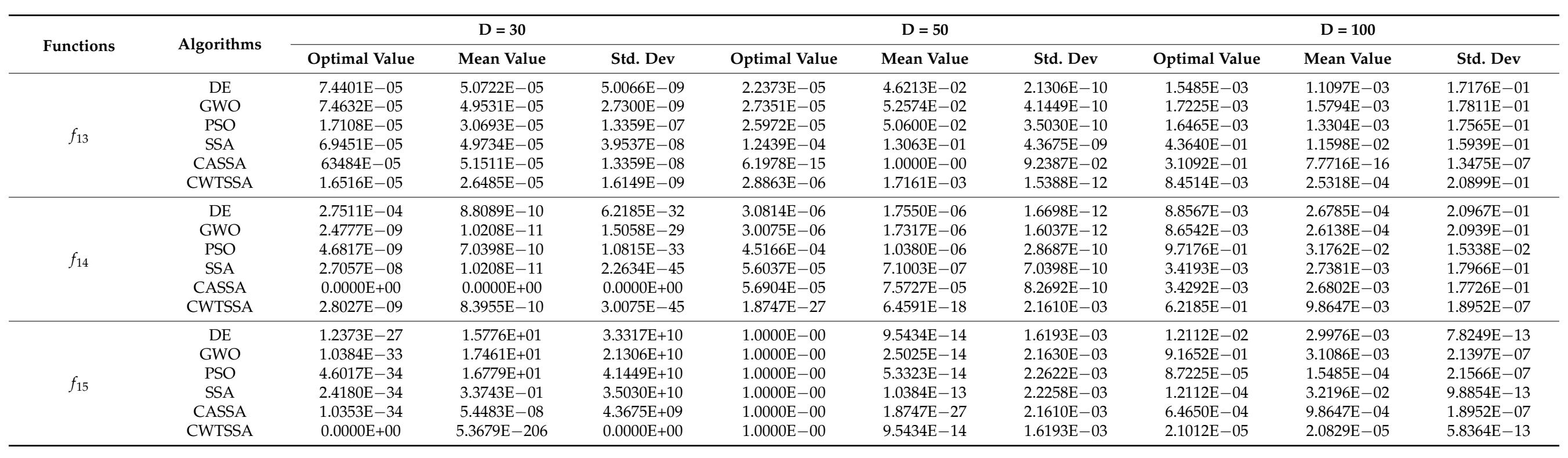




\subsubsection{Comparative Analysis of Convergence Curves}

The convergence curve in solving the benchmark functions can intuitively reflect the convergence speed and accuracy of each algorithm, and it can also clearly show the ability of the algorithm to jump out of local space. The convergence curves in solving the 15 benchmark functions $(\mathrm{D}=30)$ are shown in Figure 4.

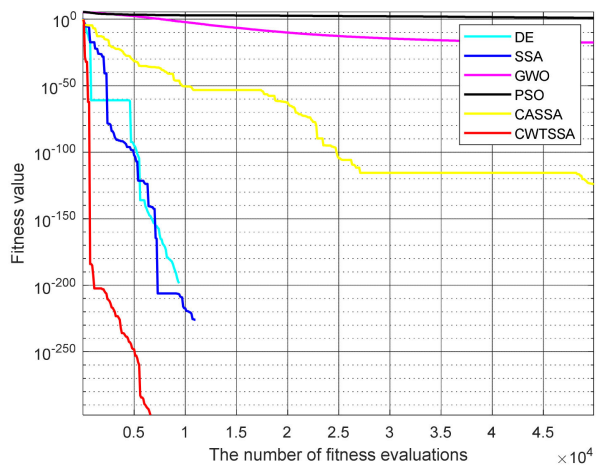

(a) Optimization process curve of $f_{1}$

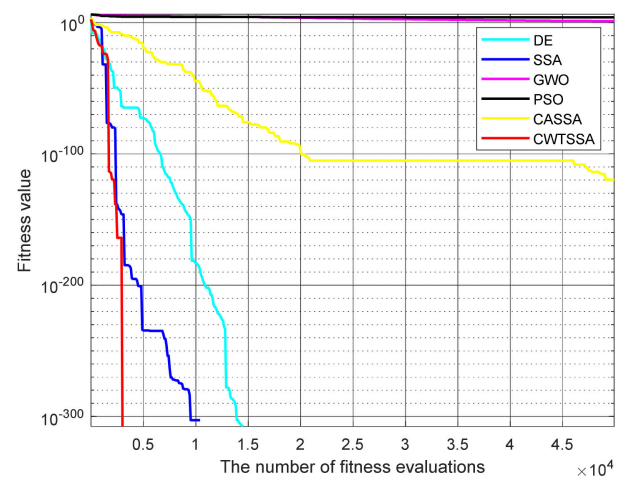

(c) Optimization process curve of $f_{3}$

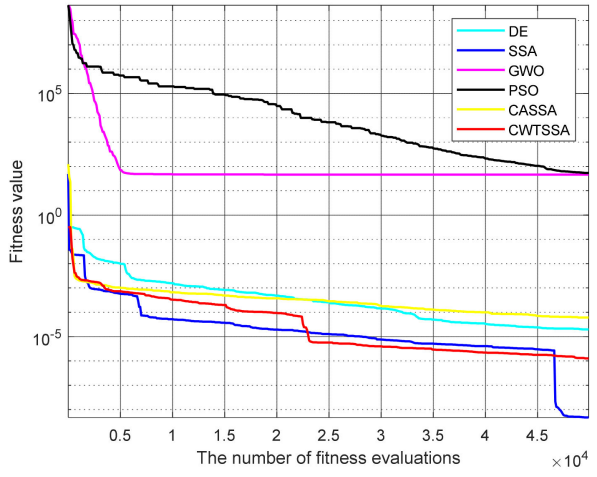

(e) Optimization process curve of $f_{5}$

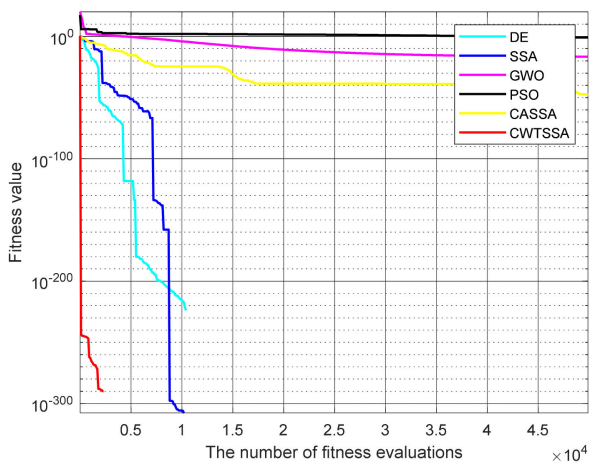

(b) Optimization process curve of $f_{2}$

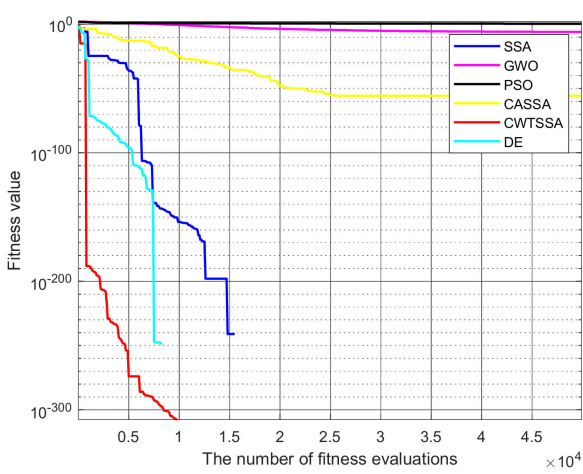

(d) Optimization process curve of $f_{4}$

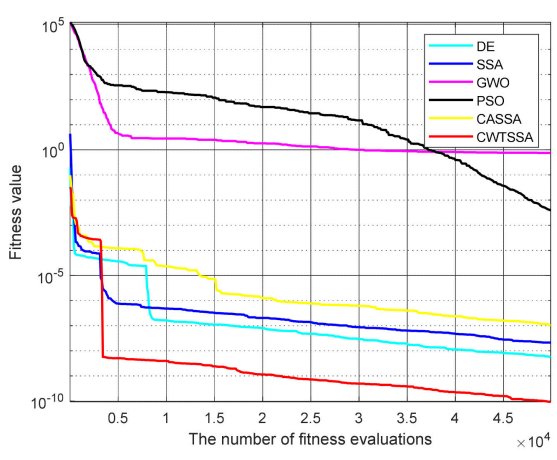

(f) Optimization process curve of $f_{6}$

Figure 4. Cont. 


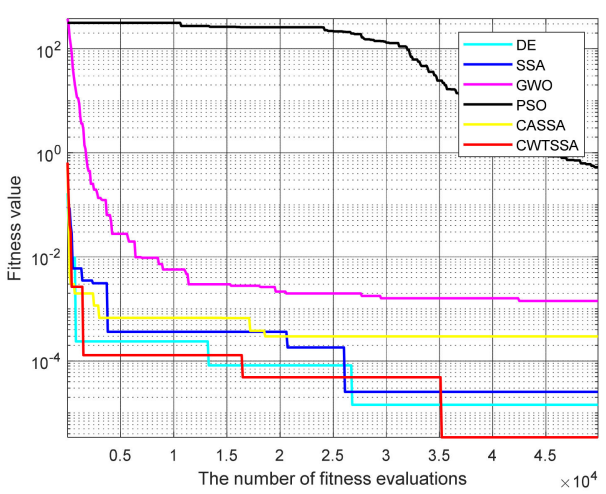

(g) Optimization process curve of $f_{7}$

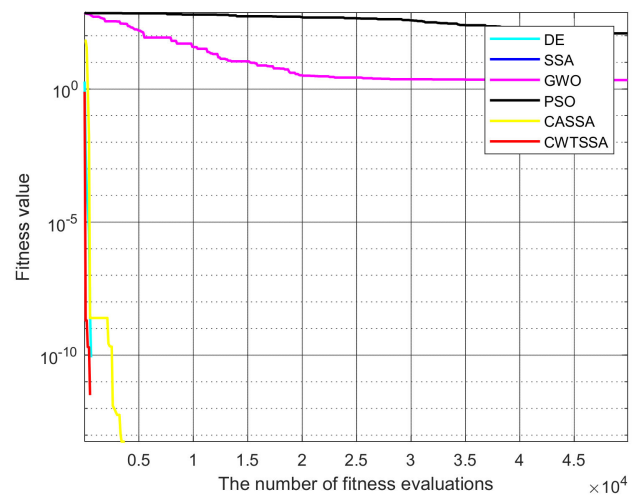

(i) Optimization process curve of $f_{9}$

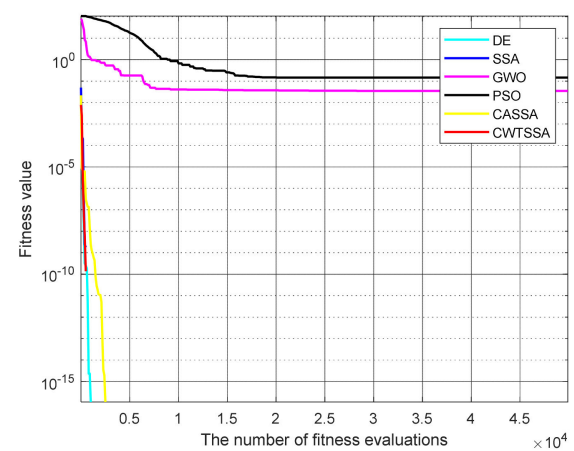

(k) Optimization process curve of $f_{11}$

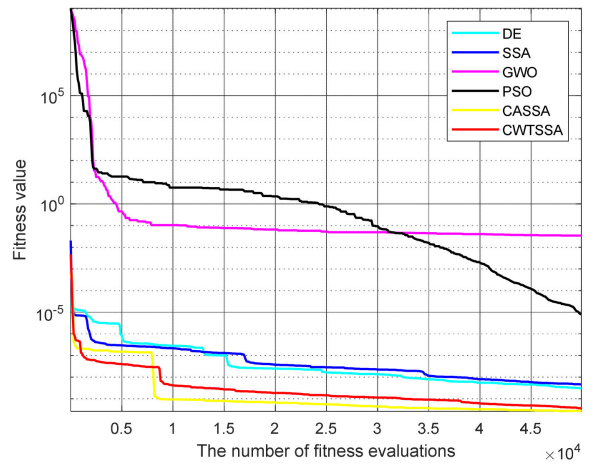

(m) Optimization process curve of $f_{13}$

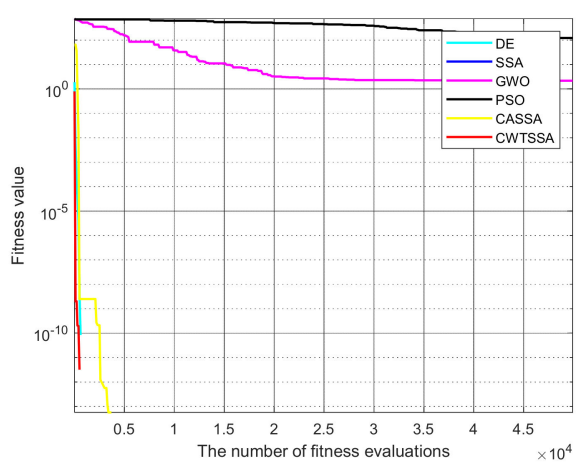

(h) Optimization process curve of $f_{8}$

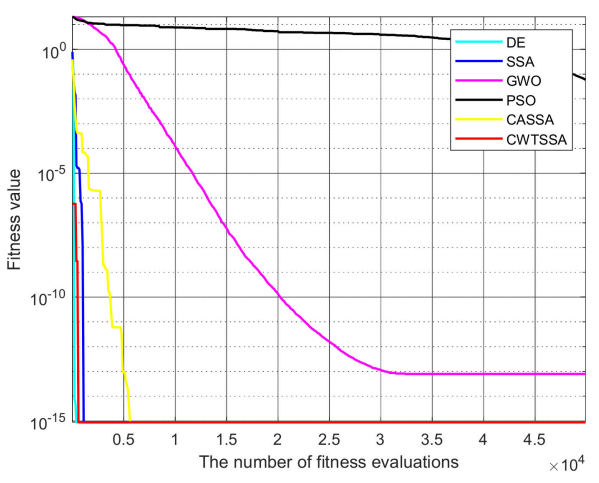

(j) Optimization process curve of $f_{10}$

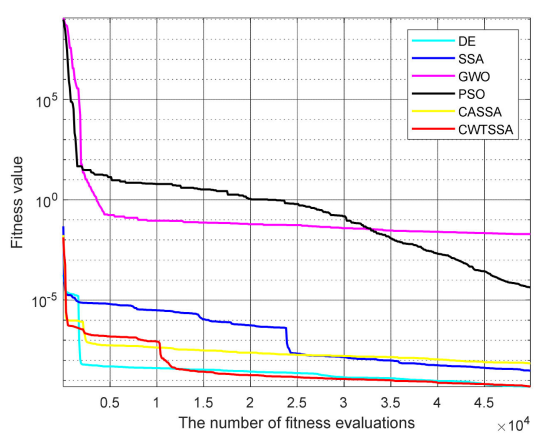

(1) Optimization process curve of $f_{12}$

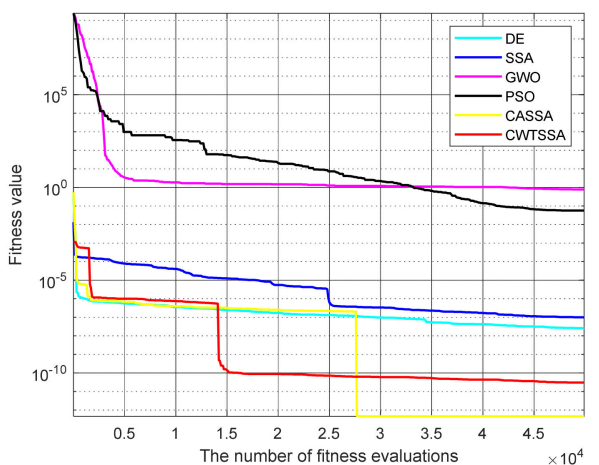

(n) Optimization process curve of $f_{14}$

Figure 4. Cont. 


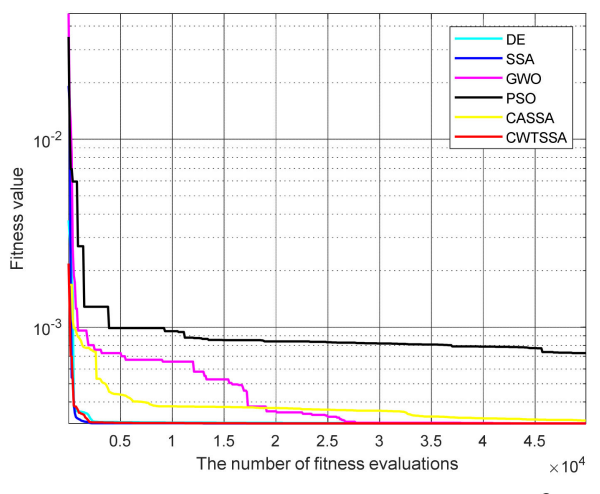

(o) Optimization process curve of $f_{15}$

Figure 4. The convergence curves of 15 test functions.

As can be seen from Figure 3, when different test functions are solved, the CWTSSA has faster search efficiency in the initial stage of the iteration, and can quickly find the convergence direction. The first inflection point indicates that the solution speed is faster. If the curve is smoother, the ability of the algorithm to jump out the local optimum is stronger.

\section{Wilcoxon Rank and Tests}

In order to verify whether there is a significant difference between CWTSSA and the other five algorithms in solving complex optimization problems, the Wilcoxon rank and test [42] is used to compare the characteristics of the performance test between the two algorithms. Wilcoxon rank and test is a non-parametric null hypothesis test statistical method, which is used to evaluate the fairness and robustness of the algorithm. Here, the null hypothesis $\mathrm{H} 0$ is selected. Equivalent in performance, the alternative hypothesis is H1. The performance of the two algorithms is significantly different. The test result $p$-value is used to compare the differences between the two algorithms. When the $p$-value is $0.05, \mathrm{H} 0$ is accepted. That is, the two algorithms have equivalent performance in global optimization. The rank sum test results for 15 test functions independently run 30 times under the dimension $\operatorname{dim}=30$ are shown in Table 5 , where " $\mathrm{S}$ " means discriminatory discrimination, and " $+/=/-$ " means that the CWTSSA is "better than/" in performance. Equivalent/inferior to other algorithms, N/A means that the performance of the two algorithms is equivalent.

Table 5. $p$-value for Wilcoxon rank.

\begin{tabular}{cccccc}
\hline \multirow{2}{*}{ Functions } & vsDE & vsGWO & vsPSO & vsSSA & vsCASSA \\
\cline { 2 - 6 } & $p$-Value $S$ & $p$-Value & $p$-Value & $p$-Value S & $p$-Value S \\
\hline$f_{1}$ & $4.76 \mathrm{E}-25+$ & $4.76 \mathrm{E}-25+$ & $4.76 \mathrm{E}-25+$ & $\mathrm{N} / \mathrm{A}$ & $\mathrm{N} / \mathrm{A}$ \\
$f_{2}$ & $4.76 \mathrm{E}-25+$ & $4.76 \mathrm{E}-25+$ & $4.76 \mathrm{E}-25+$ & $\mathrm{N} / \mathrm{A}$ & $1.12 \mathrm{E}-36+$ \\
$f_{3}$ & $4.76 \mathrm{E}-25+$ & $4.76 \mathrm{E}-25+$ & $4.76 \mathrm{E}-25+$ & N/A & $4.76 \mathrm{E}-25+$ \\
$f_{4}$ & $4.76 \mathrm{E}-25+$ & $4.76 \mathrm{E}-25+$ & $4.76 \mathrm{E}-25+$ & N/A & $4.76 \mathrm{E}-25+$ \\
$f_{5}$ & $3.34 \mathrm{E}-01-$ & $4.76 \mathrm{E}-25+$ & $4.76 \mathrm{E}-25+$ & $1.15 \mathrm{E}-01-$ & $4.76 \mathrm{E}-25+$ \\
$f_{6}$ & $1.07 \mathrm{E}-25+$ & $4.76 \mathrm{E}-25+$ & $4.76 \mathrm{E}-25+$ & $4.76 \mathrm{E}-25+$ & $4.76 \mathrm{E}-25+$ \\
$f_{7}$ & $4.76 \mathrm{E}-25+$ & $4.76 \mathrm{E}-25+$ & $4.76 \mathrm{E}-25+$ & $4.76 \mathrm{E}-25+$ & $4.76 \mathrm{E}-25+$ \\
$f_{8}$ & $1.21 \mathrm{E}-01-$ & $4.76 \mathrm{E}-25+$ & $4.76 \mathrm{E}-25+$ & $\mathrm{N} / \mathrm{A}$ & $\mathrm{N} / \mathrm{A}$ \\
$f_{9}$ & $\mathrm{~N} / \mathrm{A}$ & $4.76 \mathrm{E}-25+$ & $4.76 \mathrm{E}-25+$ & $\mathrm{N} / \mathrm{A}$ & $\mathrm{N} / \mathrm{A}$ \\
$f_{10}$ & $4.76 \mathrm{E}-25+$ & $4.76 \mathrm{E}-25+$ & $4.76 \mathrm{E}-25+$ & $4.76 \mathrm{E}-25+$ & $4.76 \mathrm{E}-25+$ \\
$f_{11}$ & $4.76 \mathrm{E}-25+$ & $4.76 \mathrm{E}-25+$ & $4.76 \mathrm{E}-25+$ & $4.76 \mathrm{E}-25+$ & $4.76 \mathrm{E}-25+$ \\
$f_{12}$ & $1.85 \mathrm{E}-01-$ & $3.92 \mathrm{E}-13+$ & $5.07 \mathrm{E}-11+$ & $5.94 \mathrm{E}-02-$ & $3.67 \mathrm{E}-02-$ \\
$f_{13}$ & $4.76 \mathrm{E}-25+$ & $4.76 \mathrm{E}-25+$ & $4.76 \mathrm{E}-25+$ & $4.76 \mathrm{E}-25+$ & $6.34 \mathrm{E}-02-$ \\
$f_{14}$ & $3.28 \mathrm{E}-25+$ & $2.16 \mathrm{E}-16+$ & $6.41 \mathrm{E}-12+$ & $4.76 \mathrm{E}-25+$ & $3.68 \mathrm{E}-09+$ \\
$f_{15}$ & $4.76 \mathrm{E}-25+$ & $4.76 \mathrm{E}-25+$ & $4.76 \mathrm{E}-25+$ & $4.76 \mathrm{E}-25+$ & $4.76 \mathrm{E}-25+$ \\
\hline
\end{tabular}


It can be seen from Table 5 that most of the $p$-values of the CWTSSA are less than 0.05 and are " + ", indicating that the CWTSSA has better performance than the other five algorithms. The performance is equivalent in the global optimization, and the optimal value can be obtained. Overall, the CWTSSA has significant advantages over the other compared algorithms.

\section{Conclusions and Future Work}

In order to enhance the search efficiency, convergence accuracy, and stability of SSA, a novel adaptive sparrow search algorithm based on integrating the chaotic mapping strategy, adaptive weighting strategy and t-distribution mutation strategy, namely the CWTSSA, was proposed in this paper. The CWTSSA uses a sine chaotic mapping strategy to initialize the population in order to enrich the diversity of solutions and speed up the exchange of information between populations. The adaptive weighting strategy and the $\mathrm{t}$-distribution mutation strategy broaden the search area of the sparrow, effectively improve the local development ability and global search ability, so as to improve the convergence accuracy of the algorithm, enhance the stability of the algorithm, and enable the algorithm to avoid falling into the local optimum. The effectiveness of the CWTSSA was tested on 12 benchmark functions. For functions $f_{1}-f_{15}$, the proposed CWTSSA achieved better results than a single strategy and combination strategy. At the same time, the CWTSSA performed well, and could even converge to the global optimal value under different dimensions in comparison with GWO, PSO and SSA. The performance was equivalent in global optimization, and the optimal value could be obtained by Wilcoxon rank and tests. To sum up, when the three strategies were used at the same time for SSA, most of the test functions had better convergence speed and convergence accuracy, and the stability was also better. This is inseparable from the use of the three strategies. In general, the SSA with each strategy shows a certain improvement in comparison with the basic SSA. From the experimental results, it can be seen that the CWTSSA had stronger optimization performance in terms of optimization accuracy, convergence speed, stability, etc.

In the next step, the CWTSSA will be applied to practical engineering problems such as image segmentation, face recognition, constraint optimization, multi-objective optimization, etc. [43]. Therefore, the aim will be to verify the ability and superiority of the CWTSSA in solving actual engineering problems, such as path planning, resource allocation, etc.

Author Contributions: Methodology, X.Y.; software, Y.L.; validation, J.L., X.Y. and P.X.; formal analysis, X.Y.; investigation, J.L. and L.Y.; resources, W.D. and L.Y.; writing-original draft preparation, X.Y.; writing-review and editing, H.C. and L.Z.; visualization, P.X. and L.Z; funding acquisition, Y.L. All authors have read and agreed to the published version of the manuscript.

Funding: This research was funded by National Natural Science Foundation of China(U2033214), the China National Key R\&D Program (2018YFB1601200), and the Research Foundation for Civil Aviation University of China (2020KYQD123), Research and Innovation Project for Postgraduates in Tianjin (Artificial Intelligence) (2020YJSZXS33).

Institutional Review Board Statement: Not applicable.

Informed Consent Statement: Not applicable.

Data Availability Statement: Not applicable.

Acknowledgments: The authors would like to thank all the reviewers for their constructive comments. The program for the initialization, study, training, and simulation of the proposed algorithm in this article was written with the tool-box of MATLAB 2019b produced by Math-Works, Inc.

Conflicts of Interest: The authors declare no conflict of interest. 


\section{References}

1. Chen, H.; Zhang, Q.; Luo, J.; Xu, Y.; Zhang, X. An enhanced bacterial foraging optimization and its application for training kernel extreme learning machine. Appl. Soft Comput. 2020, 86, 105884. [CrossRef]

2. Deng, W.; Shang, S.; Cai, X.; Zhao, H.; Zhou, Y.; Chen, H.; Deng, W. Quantum differential evolution with cooperative coevolution framework and hybrid mutation strategy for large scale optimization. Knowl.-Based Syst. 2021, 224, 107080. [CrossRef]

3. Zhou, Y.; Zhang, J.; Yang, X.; Ling, Y. Optimal reactive power dispatch using water wave optimization algorithm. Oper. Res. 2020, 20, 2537-2553. [CrossRef]

4. Niu, P.; Niu, S.; Chang, L. The defect of the Grey Wolf optimization algorithm and its verification method. Knowl.-Based Syst. 2019, 171, 37-43. [CrossRef]

5. Li, S.; Chen, H.; Wang, M.; Heidari, A.A.; Mirjalili, S. Slime mould algorithm: A new method for stochastic optimization. Future Gener. Comput. Syst. 2020, 111, 300-323. [CrossRef]

6. Li, T.; Qian, Z.; Deng, W.; Zhang, D.Z.; Lu, H.; Wng, S. Forecasting crude oil prices based on variational mode decomposition and random sparse Bayesian learning. Appl. Soft Comput. 2021, 113, 108032. [CrossRef]

7. Chen, H.; Heidari, A.A.; Chen, H.; Wang, M.; Pan, Z.; Gandomi, A.H. Multi-population differential evolution-assisted Harris hawks optimization: Framework and case studies. Future Gener. Comput. Syst. 2020, 111, 175-198. [CrossRef]

8. Wang, M.; Chen, H. Chaotic multi-swarm whale optimizer boosted support vector machine for medical diagnosis. Appl. Soft Comput. 2020, 88, 105946. [CrossRef]

9. Jin, T.; Xia, H.; Deng, W.; Li, Y.; Chen, H. Uncertain fractional-order multi-objective optimization based on reliability analysis and application to fractional-order circuit with Caputo type. Circuits Syst. Signal Process. 2021, 40, 5955-5982. [CrossRef]

10. Ma, A.X.; Zhang, X.H.; Zhang, C.S.; Zhang, B.; Gao, Y. An adaptive ant colony algorithm for dynamic traveling salesman problem. J. Inf. Sci. Eng. 2019, 35, 1263-1277.

11. Ang, K.M.; Lim, W.H.; Isa, N.; Tiang, S.S.; Wong, C.H. A constrained multi-swarm particle swarm optimization without velocity for constrained optimization problems. Expert Syst. Appl. 2020, 140, 112882. [CrossRef]

12. Li, Y.; Li, X.; Gao, L.; Meng, L. An improved artificial bee colony algorithm for distributed heterogeneous hybrid flowshop scheduling problem with sequence-dependent setup times. Comput. Ind. Eng. 2020, 147, 106638. [CrossRef]

13. Jian, G.; Dai, L.; Zhang, W. Improved genetic optimization algorithm with subdomain model for multi-objective optimal design of SPMSM. CES Trans. Electr. Mach. Syst. 2018, 2, 160-165.

14. Deng, W.; Xu, J.; Gao, X.; Zhao, H. An enhanced MSIQDE algorithm with novel multiple strategies for global optimization problems. IEEE Trans. Syst. Man Cybern. Syst. 2020, 99, 1-10. [CrossRef]

15. Jin, T.; Xia, H. Lookback option pricing models based on the uncertain fractional-order differential equation with Caputo type. J. Ambient Intell. Humaniz. Comput. 2021, 1,1-14. [CrossRef]

16. Luo, J.; Chen, H.; Heidari, A.A.; Xu, Y.; Zhang, Q.; Li, C. Multi-strategy boosted mutative whale-inspired optimization approaches. Appl. Math. Model. 2019, 73, 109-123. [CrossRef]

17. Xu, Y.; Chen, H.; Heidari, A.A.; Luo, J.; Zhang, Q.; Zhao, X.; Li, C. An efficient chaotic mutative moth-flame-inspired optimizer for global optimization tasks. Expert Syst. Appl. 2019, 129, 135-155. [CrossRef]

18. Zhong, K.; Zhou, G.; Deng, W.; Zhou, Y.; Luo, Q. MOMPA: Multi-objective marine predator algorithm. Comput. Methods Appl. Mech. Eng. 2021, 385, 114029. [CrossRef]

19. Deng, W.; Shang, S.; Cai, X.; Zhao, H.; Song, Y.; Xu, J. An improved differential evolution algorithm and its application in optimization problem. Soft Comput. 2021, 7, 5277-5298. [CrossRef]

20. Xu, Y.; Chen, H.; Luo, J.; Zhang, Q.; Jiao, S.; Zhang, X. Enhanced Moth-flame optimizer with mutation strategy for global optimization. Inf. Sci. 2019, 492, 181-203. [CrossRef]

21. Deng, W.; Xu, J.; Zhao, H.; Song, Y. A novel gate resource allocation method using improved PSO-based QEA. IEEE Trans. Intell. Transp. Syst. 2020, 99, 1-9. [CrossRef]

22. Jin, T.; Ding, H.; Li, B.; Xia, H.; Xue, C. Valuation of interest rate ceiling and floor based on the uncertain fractional differential equation in Caputo sense. J. Intell. Fuzzy Syst. 2021, 40, 5197-5206. [CrossRef]

23. Tu, J.; Chen, H.; Liu, J.; Heidari, A.A.; Pham, Q.V. Evolutionary biogeography-based whale optimization methods with communication structure: Towards measuring the balance. Knowl.-Based Syst. 2021, 212, 106642. [CrossRef]

24. Xue, J.K.; Shen, B. A novel swarm intelligence optimization approach: Sparrow search algorithm. Syst. Sci. Control Eng. 2020, 8, 22-34. [CrossRef]

25. Wang, Y.; Wang, H.; Wen, J.; Lun, Y.; Wu, J. Obstacle Avoidance of UAV Based on Neural Networks and Interfered Fluid Dynamical System. In Proceedings of the 3rd International Conference on Unmanned Systems (ICUS), Harbin, China, 27-28 November 2020; pp. 1066-1071.

26. Lv, X.; Mu, X.D.; Zhang, J. Multi-threshold image segmentation based on improved sparrow search algorithm. Syst. Eng. Electron. Technol. 2021, 43, 318-327.

27. Du, Y.; Wang, Z.M.; Li, M.H. Intrusion detection method of industrial control based on optimized nuclear extreme learning machine. Inf. Netw. Secur. 2021, 21, 1-9.

28. Zhang, C.L.; Ding, S.F. A stochastic configuration network based on chaotic sparrow search algorithm. Knowl.-Based Syst. 2021, 220, 106924. [CrossRef] 
29. Liu, T.T.; Yuan, Z.; Badami, B. Optimal brain tumor diagnosis based on deep learning and balanced sparrow search algorithm. Int. J. Imaging Syst. Technol. 2021, 46, 9541-9552. [CrossRef]

30. Liu, G.Y.; Shu, C.; Liang, Z.W.; Peng, B.H.; Cheng, L.F. A modified sparrow search algorithm with application in $3 d$ route planning for UAV. Sensors 2021, 21, 1224. [CrossRef]

31. Zhang, Z.; He, R.; Yang, K. A bioinspired path planning approach for mobile robots based on improved sparrow search algorithm. Adv. Manuf. 2021, 1-17. [CrossRef]

32. Wang, H.Z.; Wu, X.R.; Gholinia, F. Forecasting hydropower generation by GFDL-CM3 climate model and hybrid hydrologicalElman neural network model based on Improved Sparrow Search Algorithm (ISSA). Concurr. Comput. Pract. Exp. 2021, e6476. [CrossRef]

33. Liang, Q.K.; Chen, B.; Wu, H.N.; Ma, C.Y.; Li, S.Y. A novel modified sparrow search algorithm with application in side lobe level reduction of linear antenna array. Wirel. Commun. Mob. Comput. 2021, 2021, 9915420. [CrossRef]

34. Zhu, Y.L.; Yousefi, N. Optimal parameter identification of PEMFC stacks using Adaptive Sparrow Search Algorithm. Int. J. Hydrog. Energy 2021, 46, 9541-9552. [CrossRef]

35. Yuan, J.H.; Zhao, Z.W.; Liu, Y.P.; He, B.L.; Wang, L.; Xie, B.B.; Gao, Y.L. DMPPT Control of Photovoltaic Microgrid Based on Improved Sparrow Search Algorithm. IEEE Access 2021, 9, 16623-16629. [CrossRef]

36. Ouyang, C.T.; Qiu, Y.X.; Zhu, D.L. Adaptive spiral flying sparrow search algorithm. Sci. Program. 2021, 2021, 6505253. [CrossRef]

37. Yang, L.; Li, Z.; Wang, D.; Miao, H.; Wang, Z. Software defects prediction based on hybrid particle swarm optimization and sparrow search algorithm. IEEE Access 2021, 9, 60865-60879. [CrossRef]

38. Liu, T.; Yuan, Z.; Wu, L.; Badami, B. An optimal brain tumor detection by convolutional neural network and enhanced sparrow search algorithm. Proc. Inst. Mech. Eng. Part H J. Eng. Med. 2021, 235, 459-469. [CrossRef]

39. Xing, Z.; Yi, C.; Lin, J.; Zhou, Q. Multi-component fault diagnosis of wheelset-bearing using shift-invariant impulsive dictionary matching pursuit and sparrow search algorithm. Measurement 2021, 178, 109375. [CrossRef]

40. Wang, P.; Zhang, H.; Yang, H. Research on economic optimization of microgrid cluster based on chaos sparrow search algorithm. Comput. Intell. Neurosci. 2021, 2021, 1-18. [CrossRef]

41. Yong, W.; Wong, K.; Liao, X.; Chen, G. A new chaos based fast image encryption algorithm. Appl. Soft Comput. 2011, 11, 514-522.

42. Osaba, E.; Esther, V.; Javier, D.; Antonio, J.; Molinac, D.; LaTorreg, A.; Suganthanf, P.N.; Coelloe, C.A.C.; Herrerac, F. A Tutorial On the design, experimentation and application of metaheuristic algorithms to real-World optimization problems. Swarm Evol. Comput. 2021, 64, 100888. [CrossRef]

43. Derrac, J.; Garcia, S.; Molina, D.; Hreerea, F. A practical tutorial on the use of nonparametric statistical tests as a methodology for comparing evolutionary and swarm intelligence algorithms. Swarm Evol. Comput. 2011, 1, 3-18. [CrossRef] 